Review Article

\title{
Vibration Analysis for Machine Monitoring and Diagnosis: A Systematic Review
}

\author{
Mohamad Hazwan Mohd Ghazali $\mathbb{i D}^{1}$ and Wan Rahiman $\mathbb{D D}^{1,2}$ \\ ${ }^{1}$ School of Electrical and Electronic Engineering, Universiti Sains Malaysia Engineering Campus, Nibong Tebal 14300, \\ Penang, Malaysia \\ ${ }^{2}$ Cluster of Smart Port and Logistic Technology (COSPALT), Universiti Sains Malaysia Engineering Campus, Nibong Tebal 14300, \\ Penang, Malaysia \\ Correspondence should be addressed to Wan Rahiman; wanrahiman@usm.my
}

Received 4 July 2021; Revised 3 August 2021; Accepted 25 August 2021; Published 11 September 2021

Academic Editor: Gang Tang

Copyright (c) 2021 Mohamad Hazwan Mohd Ghazali and Wan Rahiman. This is an open access article distributed under the Creative Commons Attribution License, which permits unrestricted use, distribution, and reproduction in any medium, provided the original work is properly cited.

\begin{abstract}
Untimely machinery breakdown will incur significant losses, especially to the manufacturing company as it affects the production rates. During operation, machines generate vibrations and there are unwanted vibrations that will disrupt the machine system, which results in faults such as imbalance, wear, and misalignment. Thus, vibration analysis has become an effective method to monitor the health and performance of the machine. The vibration signatures of the machines contain important information regarding the machine condition such as the source of failure and its severity. Operators are also provided with an early warning for scheduled maintenance. Numerous approaches for analyzing the vibration data of machinery have been proposed over the years, and each approach has its characteristics, advantages, and disadvantages. This manuscript presents a systematic review of up-to-date vibration analysis for machine monitoring and diagnosis. It involves data acquisition (instrument applied such as analyzer and sensors), feature extraction, and fault recognition techniques using artificial intelligence (AI). Several research questions (RQs) are aimed to be answered in this manuscript. A combination of time domain statistical features and deep learning approaches is expected to be widely applied in the future, where fault features can be automatically extracted from the raw vibration signals. The presence of various sensors and communication devices in the emerging smart machines will present a new and huge challenge in vibration monitoring and diagnosing.
\end{abstract}

\section{Introduction}

Machines are widely used in today's industries and are paramount for factory operation. Careful monitoring of the machines must be done and when the machines do breakdown unexpectedly, it will cause massive loss to the company. This can be prevented by diagnosing the machine to determine the fault or potential fault such as imbalance, wear, misalignment, defective bearing, friction whirl, and cracking teeth in gearing $[1,2]$. Several available diagnosis methods have been applied over the years including oil analysis, vibration signal analysis, particle analysis, corrosion monitoring, acoustic signal analysis, and wear debris analysis [3,4]. Among these analyses, acoustic and vibration signal analysis emerge as popular choices because many faults can be identified without stopping the machine or tearing the machine down. The changes of these signals often indicate the presence of a fault. Acoustic analysis has the advantages of short analysis time, high recognition efficiency, and nondestructive testing. However, it is very challenging to properly capture the acoustic signals due to several factors such as environmental conditions, different parameter of recording software, and reflected acoustic signals [5]. Vibration signals analysis also has some advantages and disadvantages. Real-time machine monitoring can be achieved using vibration analysis and there are many well-developed signal processing techniques that can be applied. The limitations of vibration analysis are noise contamination and proper mounting position of the vibration sensors [6]. Another technique that can be used for 
machine monitoring and diagnosis is thermal imaging analysis. In this analysis, an infrared camera is usually used to detect many electrical faults in the machine based on the thermal anomalies. The thermal images obtained are useful in detecting and locating the machine's faults. However, this technique is expensive and requires a longer time to process the thermal images compared to processing the acoustic and vibration signals. Vibration analysis is considered as the best method in determining the machine condition [7]. According to Saucedo-Dorantes et al. [8], the percentage of fault diagnosis techniques conducted with the means of vibration analysis exceeds $82 \%$. Machines are mostly made up of moving parts that generate unwanted vibration and with vibration analysis, and a decision on whether the machine can continue to operate or needs to be shut down and repaired can be made [3].

The machine's condition can be determined by the vibration amplitude and frequency, as both can reveal the severity and source of the machine problem, respectively [9]. At first, without the help of vibration equipment, machine conditions can still be diagnosed with a human brain of trained personnel coupled with the senses of touch and hearing which acts as a vibration analyzer. However, human perception is somewhat limited, and it is impossible to detect problems that are beyond the capability of human senses of touch and hearing. Then, vibration analysis was based on a real-time spectral analyzer and now it can be categorized into time, frequency, and time-frequency domain [10]. Time and frequency domain analysis analyses the time series of data with respect to time and frequency, respectively. Timefrequency domain analysis used both time and frequency domains at the same time [3]. Vibration analysis for most machine monitoring and diagnosis can be divided into lowspeed and high-speed machines. Because currently there is no universally accepted speed range to differentiate both types of machines, machines with rotating speeds up to $600 \mathrm{rpm}$ such as wind turbines and paper mills are considered low-speed machines. According to Kim et al. [11], low-speed machines can be very time-consuming and more difficult to monitor compared to high-speed machines as the rotating elements and the fault is typically low unless the fault has reached above the background noise level. Vibration monitoring of low-speed machines is highly associated with low-speed bearing in ensuring the reliability of the machine.

The vibration analysis for machine monitoring and diagnosis typically consists of three main steps, which are data acquisition, signal processing, and fault recognition. To date, there are lots of techniques and instruments used in each of the aforementioned steps, and choosing the right ones might be quite challenging. This is because each method and instrument have its characteristics, advantages, and disadvantages. These methods can be divided into two main groups which are model-based and datadriven methods. Model-based methods require an analytical model of the system whereas data-driven methods do not need any assumption about the system's model. In data-driven methods, advanced signal processing techniques are applied. Because it is very difficult to model a faulty system, data-driven methods are widely applied in machine diagnosis and monitoring compared to modelbased methods. Thus, the main contribution of this article is the review of various data-driven vibration analysis techniques and instruments used for monitoring and diagnosing the machines. However, due to a wide range of techniques, only the widely used ones are discussed in this article. There are several review articles regarding this area, and Table 1 discusses each of the review articles. Based on Table 1, we aimed to fill the research gap in reviewing the vibration analysis for machine monitoring and diagnosis, where the data acquisition system and comparison between different vibration analysis techniques including the latest deep learning approach are not discussed. We also aimed to answer the following research questions described in Table 2.

This manuscript is organized as follows. In the next section, the research approach for this review article is discussed. Then, Sections 3-5 will follow the vibration analysis steps, as shown in Figure 1. Firstly, in Section 3, the data acquisition stage is discussed. This stage involves the types of vibration sensors used to obtain the vibration data and analyzers for analyzing the acquired data. The data acquisition stage is not discussed in most of the published review articles. Besides, different sensor mounting techniques are also discussed in this section. Section 4 is about the signal processing or feature extraction methods performed by researchers over the years, based on the time, frequency, and time-frequency domains. The final stage in vibration analysis, which is the fault recognition stage, is discussed in Section 5. In this section, different AI-based methods such as support vector machine (SVM), neural network (NN) including deep learning, fuzzy logic, and genetic algorithm (GA) in the fault recognition step are discussed. The discussions and findings of our review are explained in Section 6, and we conclude our studies in Section 7.

\section{Research Approach}

A comprehensive literature study was conducted to answer the five research questions. A Systematic Literature Review (SLR) approach was employed to collect the relevant primary studies regarding the vibration analysis for machine monitoring and diagnosis [17]. Firstly, we classified the articles and the selected papers were then analyzed and differentiated through the content analysis method. The results can be classified into four main categories:

(1) Survey, where review articles made by other researchers on vibration analysis for machine monitoring and diagnosis are discussed.

(2) Simulation, where the performance of the proposed technique is evaluated through simulation methods.

(3) Experiment/real-time deployments, where the methods developed are applied experimentally or in real environments. 
TABLE 1: List of review articles or survey regarding vibration analysis for machine monitoring and diagnosis.

\begin{tabular}{|c|c|c|}
\hline Authors & Scope & Comments \\
\hline $\begin{array}{l}\text { Vishwakarma et al. } \\
\text { [12] }\end{array}$ & $\begin{array}{l}\text { esented a review of some vibrati } \\
\text { ethods applied to different types }\end{array}$ & $\begin{array}{l}\text { No discussion on the data acquisition } \\
\text { based fault recognition techn }\end{array}$ \\
\hline Kumar et a & $\begin{array}{l}\text { Reviewed various techniques including the AI me } \\
\text { used for fault diagnosis based on vibration anal } \\
\text { methods }\end{array}$ & $\begin{array}{l}\text { No discussion on the data acquisi } \\
\text { comparison between different fea } \\
\text { fault recognition methods are }\end{array}$ \\
\hline Boud & $\begin{array}{l}\text { Presented the vibration analysis } \\
\text { their capabilities, advantages, } \\
\text { monitoring rolling elen }\end{array}$ & Only discussed four \\
\hline Aher & $\begin{array}{l}\text { Discussed a variety of vibration a } \\
\text { diagnosing the rotating machine } \\
\text { methods }\end{array}$ & $\begin{array}{l}\text { No discussion on the dat } \\
\text { review was conducted in } 2 \\
\text { methods such }\end{array}$ \\
\hline $\begin{array}{l}\text { Sait and Sharaf- } \\
\text { Eldeen [15] }\end{array}$ & $\begin{array}{l}\text { Presented a review of vibra } \\
\text { detection techniques to } \mathrm{m}\end{array}$ & $\begin{array}{r}\text { No discussion o } \\
\text { domai }\end{array}$ \\
\hline Sadeghi & $\begin{array}{r}\text { Discussed on the fault } \mathrm{d} \\
\text { machines using }\end{array}$ & $\begin{array}{r}\text { Most of the vibr } \\
\text { disc }\end{array}$ \\
\hline
\end{tabular}

(4) Performance comparison, where the proposed technique is utilized and compared with other methods in terms of accuracy or robustness.

The databases used for the electronic search were Multidisciplinary Digital Publishing Institute (MDPI), Institute of Electrical and Electronics Engineers (IEEE) Xplore, Association for Computing Machinery (ACM) Digital Library, ScienceDirect, Web of Science, Wiley Online Library, Researchgate, Springer, Scopus, and Google Scholar. To refine the search results, a set of inclusion and exclusion criteria is used in determining the relevant articles, which can be observed in Table 3 .

The article searching process starts by selecting the main search term: "machine monitoring" or "machine diagnosis." The second search term was "vibration analysis." So, the search sentence was as follows: "machine monitoring" OR "machine diagnosis" AND "vibration analysis." The reason why we decided to use these simple keywords is to get good coverage of potential studies. Next, we refine the search terms by adding the "artificial intelligence" term such as SVM, NN, deep learning, fuzzy logic, and GA as the third term. The first and second search terms are retained. The aim is to obtain the missing articles after searching with the "machine monitoring" or "machine diagnosis" and "vibration analysis" terms. 100 related studies were targeted to provide enough information for categorization and research trends. Next, we classified all the selected articles into the aforementioned categories. The total number of suitable articles collected was 105 , and some of the articles could be classified into more than one category.

\section{Data Acquisition Methods (RQ 1)}

According to Elango et al. [10], a trained worker without academic qualifications can carry out the data collection work but data processing work in determining the condition of the machine requires an engineer. Referring to Figure 2, there are two instruments that are crucial in the data collecting stage which are analyzer and sensor. Vibration analyzer can be divided into standalone and computer-based analyzer, whereas vibration sensor consists of accelerometer, velocity transducer, displacement sensor, and laser Doppler vibrometer (LDV). The accelerometer can be further divided into piezoelectric and microelectromechanical system (MEMS) accelerometer.

\section{Analyzer}

Analyzer is an instrument used to analyze the vibration data produced by machinery. It is composed of a sensor (which is presented in the later section of this paper), amplifier, filter, and $\mathrm{A} / \mathrm{D}$ converter. The signal from the vibration sensor passes through the amplifier to increase the resolution and signal-to-noise ratio. The amplified signal then passes through a filter so that aliasing would not be encountered in the digitization stage. The signal is digitized in A/D converter, and then it goes through the processing unit where it can be portrayed as a time waveform or can be further processed to acquire frequency spectrum [10, 18]. The vibration analyzer can be divided into conventional and computer-based vibration analyzer. A conventional vibration analyzer is a standalone instrument that is specifically built for vibration. It is a complex and expensive instrument, usually used by vibration experts. This instrument can help the user to determine the presence of a problem as well as its root cause and time for the machine to fail. There are single, dual, and four-channel analyzers available in the market. A single channel analyzer can only receive an input from one accelerometer at a time, whereas a dual-channel analyzer can receive inputs from two differently placed accelerometers at the same time [19]. A four-channel analyzer can accept input from multiple sensors and capable of measuring horizontal, vertical, axial, and early bearing detection simultaneously. It is usually used with a triaxial accelerometer. The key advantage of a four-channel analyzer is the ability to observe the operating deflection shape (ODS) of a machine. Nuawi et al. [20] used a four-channel vibration analyzer in the monitoring process of bearing condition and the application of a dual-channel analyzer for machine monitoring can be seen in $[21,22]$. Another cheaper alternative is a handheld vibration meter. This battery-powered device is equipped 
TABLE 2: The research questions aimed to be answered in this study.

\begin{tabular}{|c|c|}
\hline RQ & Motivation \\
\hline $\begin{array}{l}\text { RQ 1: what are the current and future instruments used for the } \\
\text { machine's vibration data acquisition process? }\end{array}$ & $\begin{array}{l}\text { The answer to this question helps to determine the best instrument } \\
\text { to be applied for respective vibration analysis. }\end{array}$ \\
\hline $\begin{array}{l}\text { RQ 2: what are the most used vibration signal processing techniques } \\
\text { and the comparison between them including the advantages and } \\
\text { limitations of each method? }\end{array}$ & $\begin{array}{l}\text { Answering this question can help to determine the most applied } \\
\text { techniques and identifying the benefits and drawbacks of each } \\
\text { vibration's signal processing methods. }\end{array}$ \\
\hline $\begin{array}{l}\text { RQ 3: what are the latest AI techniques used in machine vibration } \\
\text { monitoring and diagnosis, and how does it perform compared to } \\
\text { other widely used AI methods? }\end{array}$ & $\begin{array}{l}\text { By answering this question, the latest AI method applied in machine } \\
\text { vibration monitoring and diagnosis can be identified and the } \\
\text { performance can be compared with the widely used AI methods. }\end{array}$ \\
\hline $\begin{array}{l}\text { RQ 4: what are the future directions regarding vibration analysis for } \\
\text { machine monitoring and diagnosis? }\end{array}$ & $\begin{array}{l}\text { The answer to this question can help new researchers fill the research } \\
\text { gap regarding this area. }\end{array}$ \\
\hline RQ 5: what are the most influential articles $f$ & $\begin{array}{l}\text { Answering this question can help the readers identify the articles that } \\
\text { can be used as references for their research. }\end{array}$ \\
\hline
\end{tabular}

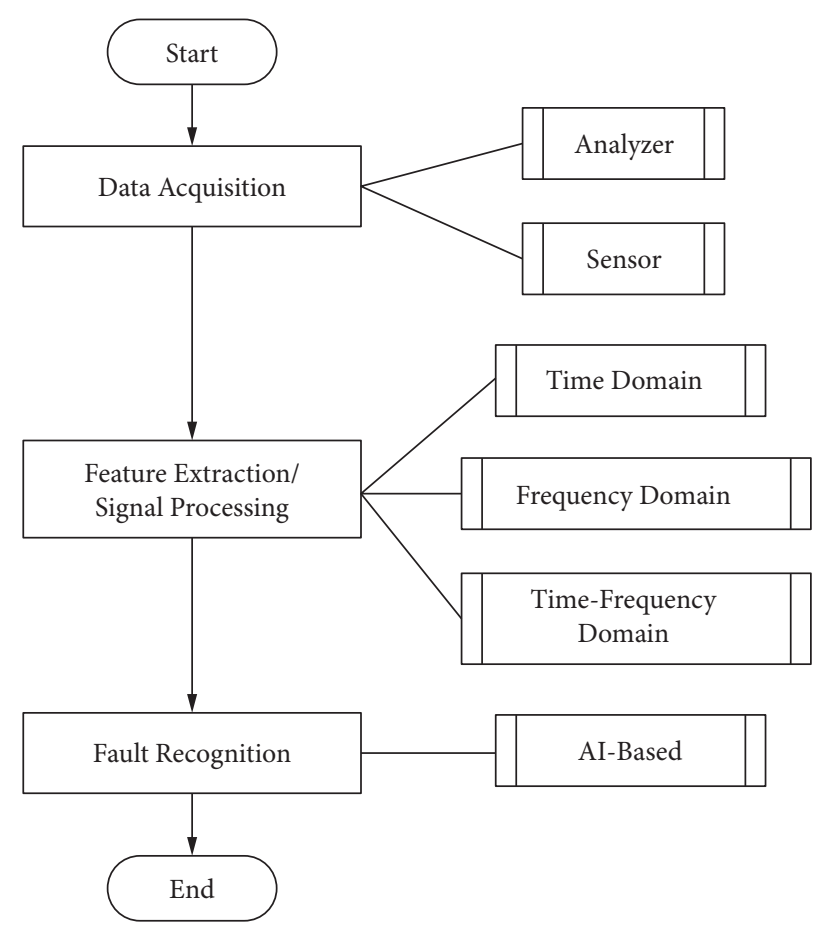

Figure 1: The framework of the article where data acquisition stage is discussed first, followed by feature extraction techniques, and fault recognition approaches based on AI.

with an accelerometer and provides a display of vibration levels when in contact with machinery [19]. It requires very little skill to use but its measurement capability is somewhat limited and lacking in data storage performance.

A computer-based vibration analyzer is an emerging instrument where vibration data can be processed virtually with the help of specific software and a personal computer. This method has gained popularity because it is simple, inexpensive, and easy to repair, and can perform most of the functions available in the conventional vibration analyzer such as oscilloscope, multimeter, and waveform generator. LabVIEW is a widely used programming language in this method due to numerous arrays of data acquisition cards and measurement systems supported by it [23-25]. Ansari and Baig [23] used the computer-based vibration analyzer to monitor the condition of the machine, and they found that a conventional vibration analyzer is faster and more accurate. To overcome these limitations, dedicated hardware such as Digital Signal Processor (DSP) or Field Programmable Gate Array (FPGA) was used alongside a personal computer and sensor for user control and result display [18]. The computer processor usually has to handle the whole operating system in addition to the virtual analyzer whereas the DSP only performs one task. This makes the vibration analysis faster in a computer equipped with DSP. In [26], vibration analysis on the rotating machine has been conducted by employing two DSPs. Rangel-Magdaleno et al. [27] has conducted a vibration analysis on the CNC machine using an FPGA device. FPGA played a role in processing the vibration data and the computer screen portrayed the results obtained for further analysis. Rodriguez-Donate et al. [28] developed an online monitoring system for the induction motor with the 
TABLE 3: The inclusion and exclusion criteria used for articles searching in this study.

\begin{tabular}{|c|c|}
\hline Inclusion criteria & $\begin{array}{c}\text { Exclusion } \\
\text { criteria }\end{array}$ \\
\hline Articles should fall into one of the four categories mentioned in this study & $\begin{array}{l}\text { Articles that are } \\
\text { not written in } \\
\text { English }\end{array}$ \\
\hline Articles should meet both the search terms & $\begin{array}{l}\text { Articles that are } \\
\text { not related to } \\
\text { the vibration } \\
\text { analysis for } \\
\text { machine } \\
\text { monitoring and } \\
\text { diagnosis }\end{array}$ \\
\hline Articles are published or accepted during the period between 1996 and 2021 (covering 25 years period) & $\begin{array}{l}\text { Duplicated } \\
\text { articles }\end{array}$ \\
\hline $\begin{array}{l}\text { Articles should be listed at least in one of the research databases } \\
\text { Articles should be published or accepted at a conference, journal, magazines, or theses }\end{array}$ & \\
\hline
\end{tabular}

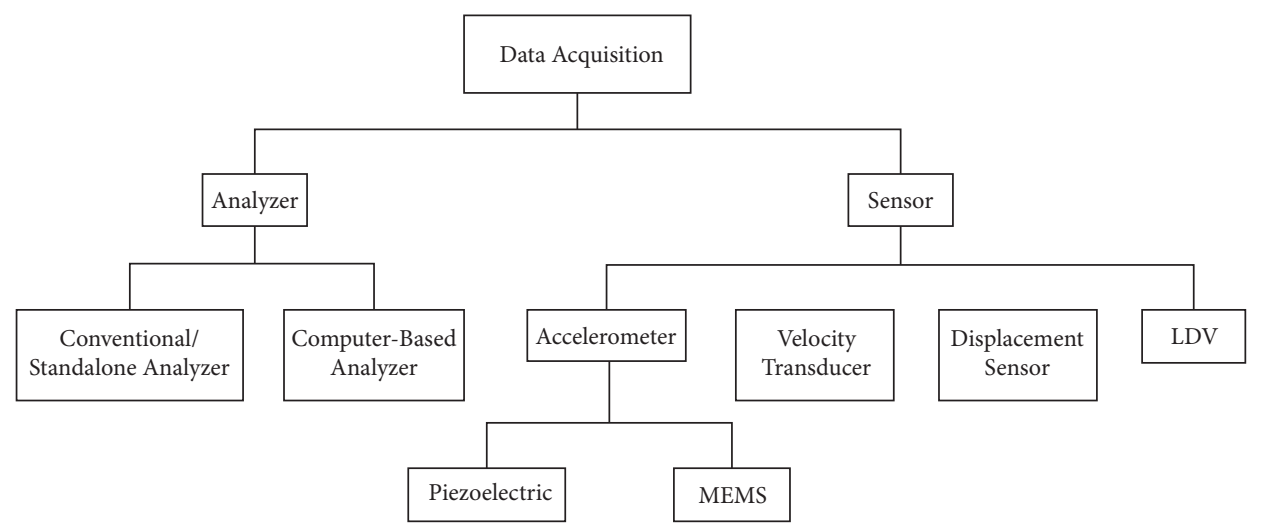

FIgURE 2: The data acquisition stage of the proposed review article.

implementation of FPGA, and they found that the FPGAbased system has better processing speed compared to DSP and all the peripheral digital structures and processing unit can be included in a single chip. Compared to DSP, a computer-based vibration analyzer using FPGA is better because it can achieve true parallelism. Both devices actually provide better performances than using only a computerbased vibration analyzer [18]. More information regarding DSP and FPGA analyzers can be found in [29-31].

\section{Sensor}

A sensor or transducer is a device that converts mechanical signals to electrical signals [32]. The type of sensors used is usually based on the frequency range, sensitivity, design, and operational limitations. No matter what type of sensors is used, the stiffer the mounting of the sensor, the higher the frequency range and its reading accuracy [33]. In vibration analysis, there are three widely used sensors for acquiring the vibration signal. These sensors are accelerometer, velocity, and displacement sensor. The noncontact LDV sensor is also discussed in this section. The advantages and disadvantages of each vibration sensor can be seen in Table 4 .
5.1. Sensor Mounting Method. Choosing a mounting method as well as implementing it correctly is an important factor in vibration data collection. For continuous or online monitoring of machine condition, vibration sensors are usually mounted permanently at a specific location in the machine. Mounting can be divided into four main methods, namely, stud-mounted, adhesive-mounted, magnet-mounted, and nonmounted. Stud mounting is usually preferable for permanent mounting applications. The sensor is screwed in a stud and secured to the machine. Apart from highly reliable and secure, this mounting technique has the widest frequency response compared to other methods. Make sure that the location where the sensor is going to be mounted is clean and paint free because any irregularities in the mounting surface will produce improper measurements or worst, damage to the sensor itself [19]. For adhesive mounting, no extensive machining is required as epoxy, glue, or wax will be applied. If the machine cannot be drilled for stud mounting, adhesive mounting is generally the best alternative. Although this mounting technique is easy to apply, the accuracy of the measurement is reduced because of the presence of damping in the adhesive [19]. In addition to that, it is also more difficult to remove the sensor compared to other mounting methods. The magnetic mounting method is 
usually limited to temporary applications with a portable analyzer and not preferable for permanent monitoring because the high-frequency signals might be disrupted. The nonmounting method is typically applied by a probe tip, where there is no external mechanism between the transducer and the target surface. It is usually used in areas that are difficult to reach. The length of the probe tip, however, will affect the measurement, with longer probes lead to more inaccuracies.

5.2. Accelerometer. An accelerometer is a device used to measure the vibration or acceleration of a structure in the SI unit of $\mathrm{g}(\mathrm{m} /)$. The working mechanism is that when the piezoelectric material in the accelerometer is subjected to a force, it produces a charge corresponding to the force applied. Because force is directly proportional to the acceleration, any change to this factor will produce a change in the charge produced, which is then amplified [33]. Uniaxial accelerometer can only detect movement in one plane, whereas triaxial accelerometer covers all the three dimensions. Compared to the uniaxial accelerometer, triaxial accelerometer has a higher memory capacity but much more expensive [34]. Accelerometer is a widely used sensor due to its reliability, simplicity, and robustness. It can be further divided into a piezoelectric and MEMS accelerometer. Piezoelectric accelerometer relies on the piezoelectric effect of quartz or ceramic crystals, which are usually preloaded, to generate an electrical output that is proportional to the applied acceleration. Changes in the charge produced depend on this acceleration $[35,36]$. Piezoelectric accelerometer possesses several advantages such as better frequency and dynamic range, lightweight, and high sensitivity. However, it is vulnerable to interference from the external environment [37]. It also requires electronic integration in order to obtain velocity and displacement data because it is AC coupled [37]. Salami et al. [38] demostrated the application of LabVIEW in monitoring and analyzing the vibration signals, where piezoelectric accelerometer was used in their study. Igba et al. [39] installed the piezoelectric accelerometer sensor on the operational turbines to obtain the vibration data for time domain analysis. Khadersab and Shivakumar [40] used the piezoelectric accelerometer to obtain vibration data from rotating machinery to analyze the bearing faults. Figure 3(a) shows the vibration measurement piezoelectric accelerometer.

MEMS accelerometer usually consists of movable proof mass with plates, supported by a mechanical suspension system to the frame [41]. When it is subjected to acceleration, the proof mass tends to resist motion due to its own inertia and therefore the spring is stretched or compressed. As a result, force corresponds to the applied acceleration is created. MEMS accelerometer is DC coupled and very suitable for measuring low-frequency vibration and acceleration. It requires low processing power and provides superior sensitivity [41]. Modern MEMS accelerometer provides quite good data quality up to several tens of $\mathrm{kHz}$. The drawback is that it suffers from a poor signal-to-noise ratio. Contreras-Medina et al. [42] used a low-cost MEMS accelerometer in detecting machinery failures. Chaudhury et al. [41] used the MEMS accelerometer in different rotating machines for vibration monitoring. A performance comparison between conventional piezoelectric accelerometer and MEMS accelerometer can be seen in [43, 44]. It was found that MEMS accelerometer's sensitivity is more stable compared with the piezoelectric accelerometers and this low-cost MEMS accelerometer can be a good alternative to the high-cost piezoelectric accelerometer. This sensor has also been applied in $[26,39]$.

5.3. Velocity Transducer. A velocity transducer measures the voltage produced by the relative movement of the object, usually in the $\mathrm{m} / \mathrm{s}$ or $\mathrm{cm} / \mathrm{s}$ unit. It works based on the concept of electromagnetic induction, and it can operate without any external device [45]. As the surface where the sensor is mounted vibrates, the movement of the magnet in the coil will produce a voltage proportional to the velocity of the vibration [46]. This voltage signal represents the vibration produced and is then feeds a meter or analyzer [33]. Velocity sensors are not recommended when diagnosing the high-speed machinery because the operational frequency range is limited from $10 \mathrm{~Hz}$ to $2 \mathrm{kHz}$ [10]. Generally, velocity transducer costs less than other sensors and coupled with its easy installation feature, it is favorable in monitoring the vibration of rotating machinery. However, it is big, heavy, and most velocity transducers are prone to reliability problems at operational temperatures that exceed $121^{\circ} \mathrm{C}$ $[37,47]$. A velocity transducer was applied by Rossi [48] to measure the frame vibration of compressor, which usually comprises of frequencies below $10 \mathrm{~Hz}$. Figure 3(b) shows the vibration measurement using velocity transducer.

5.4. Displacement Sensor. A displacement sensor, which is sometimes called eddy current or proximity sensor measures both relative vibration and position of the shaft. The displacement unit can be in $\mathrm{m}, \mathrm{cm}$, or $\mathrm{mm}$. It is usually used in measuring low-frequency vibration of less than $10 \mathrm{~Hz}$, but it can also measure vibration up to $300 \mathrm{~Hz}$ [45]. However, they do not excel in measuring a shaft bending away from the probe location [47]. Unbalance and misalignment problems are the types of problems that can be detected by the displacement probe. For the measured vibration frequencies above $1 \mathrm{kHz}$, the amplitude is usually lost in the noise level [47]. It has the advantages of a good dynamic range within a specific frequency range, reasonable sensitivity, and a simple postprocessing circuit with negligible maintenance. However, it is difficult to install, susceptible to shocks, and some traditional displacement sensors are not calibrated for unknown metal materials [37]. Sarhan et al. [49] used the displacement sensor in monitoring the cutting forces of the machining center under different cutting conditions. Saimon et al. [50] developed a low-cost fiber optic displacement sensor (FODS) for industrial applications that is immune to electromagnetic interference. The capability of a fiber optic displacement sensor in capturing the amplitude and frequency of vibration was studied by Binu et al. [51], and based on the results, this sensor can solve many sensing problems in aircraft. 
TABLE 4: The advantages and disadvantages of various sensors used in vibration analysis for machine monitoring and diagnosis.

\begin{tabular}{|c|c|c|}
\hline Sensors & Advantages & Disadvantages \\
\hline $\begin{array}{l}\text { Piezoelectric } \\
\text { accelerometer }\end{array}$ & $\begin{array}{l}\text { Lightweight, high sensitivity, good } \\
\text { frequency, dynamic range }\end{array}$ & $\begin{array}{l}\text { Needs electronic integration to acquire velocity and displacement data, } \\
\text { vulnerable to interference from the external environment }\end{array}$ \\
\hline $\begin{array}{l}\text { MEMS } \\
\text { accelerometer }\end{array}$ & $\begin{array}{l}\text { Cheaper than piezoelectric sensor, } \\
\text { requires low processing power, high } \\
\text { sensitivity }\end{array}$ & Suffers from poor signal-to-noise ratio \\
\hline $\begin{array}{l}\text { Velocity } \\
\text { transducer }\end{array}$ & $\begin{array}{l}\text { Can operate without any external device, } \\
\text { generally costs less than other sensors }\end{array}$ & $\begin{array}{l}\text { Limited operational frequency range, most velocity transducers are prone } \\
\text { to reliability problems at operational frequency of more than } 121^{\circ} \mathrm{C}\end{array}$ \\
\hline $\begin{array}{l}\text { Displacement } \\
\text { sensor }\end{array}$ & $\begin{array}{l}\text { Good sensitivity, simple postprocessing } \\
\text { circuit with negligible maintenance }\end{array}$ & Succeptible to shock, difficult to install \\
\hline LDV & $\begin{array}{l}\text { Ease of changing the measurement } \\
\text { points, ability to provide long-range } \\
\text { measurements without compromising } \\
\text { the signal quality }\end{array}$ & Extremely high cost, limited portability \\
\hline
\end{tabular}

5.5. $L D V$. LDV is a noncontact optical measurement instrument that can be applied to determine the vibration velocities of any points on the surface of a particular machine $[52,53]$. The working mechanism of LDV is based on the laser Doppler concept where a frequency-modulated coherent laser beam is reflected from a vibrating surface, and Doppler shift of the reflected beam is compared with the reference beam,. Currently, a higher power infrared (invisible) fiber laser is more popular in LDV compared to the He-Ne laser. The introduction of this technology has fulfilled the goal of achieving long-range measurements without compromising the signal quality [54]. Continuous-scan laser Doppler vibrometry (CSLDV) has accelerated the measurement at many points. The laser beam will scan continuously along a defined path across a structure according to the desired scan frequencies. One major advantage of LDV is the ease of changing the measurement point, which can be done by just deflecting the laser beam. Despite that, the application of LDV in machine monitoring and diagnosis is limited because of the price and portability factors.

\section{Feature Extraction/Signal Processing Method (RQ 2)}

Figure 4 shows the feature extraction/signal processing stage involved in this study. It can be divided into time, frequency, and time domain frequency analysis. The time domain analysis involves the statistical features of peak, root-meansquare (RMS), crest factor, and kurtosis. The frequency domain analysis consists of fast Fourier transform (FFT), cepstrum analysis, envelope analysis, and spectrum analysis, whereas time-frequency domain analysis can be divided into WT, Hilbert-Huang transform (HHT), Wigner-Ville distribution (WVD), short-time Fourier transform (STFT), and Power Spectral Density (PSD).

\section{Time Domain Analysis}

The simplest vibration analysis for machine diagnosis is used to analyze the measured vibration signal in the time domain. Vibration signals obtained are a series of values representing proximity, velocity, and acceleration, and in time domain analysis, the amplitude of the signal is plotted against time.
Although other sophisticated time domain approaches have been used, the approach of visually looking at the time waveform should not be underestimated because numerous information can be obtained in this manner. This information includes the presence of amplitude modulation, shaft unbalance, transient, and higher-frequency components [55]. However, simply looking into these vibration signals cannot segregate the variations in vibration signals for different machine failures due to the noisy data, especially at the early stage of failure. Thus, a signal processing method is required to obtain the important information from the time domain signals by converting the raw signals into appropriate statistical parameters such as peak, RMS, crest factor, and kurtosis. Several statistical parameters are usually extracted from the time domain signal so that the most significant parameter, which can effectively differentiate between healthy and defective machine vibration signals, can be chosen [56]. In this article, the statistical parameters of peak, RMS, crest factor, and kurtosis are discussed and the advantages and disadvantages of each parameter can be seen in Table 5.

7.1. Peak. The peak is the maximum value of the signal, $v(t)$, over measured time and can be defined as [55]

$$
\text { peak }=|v(t)| \max .
$$

If there is a presence of impacts, the peak values of the vibration signal will vary. Under a fault condition, the peak value increases. The fault's severity and type can be assessed based on the amplitudes of the corresponding peaks. Peak value feature was studied by Lahdelma and Juuso [57] to diagnose bearing and gear faults in the machine. The proposed approach is suitable for online analysis as the requirements for frequency range are small. Shrivastava and Wadhwani [58] used statistical parameters such as peak, RMS, crest factor, and kurtosis to diagnose the rotating electrical machine. Although all parameters can differentiate between healthy and faulty conditions, they concluded that determining the type of faults in this manner is not very efficient. Igba et al. [39] used the peak values approach in monitoring the condition of wind turbine gearboxes because faults can be detected based on the changes in their values. 
This approach can also counter the limitations of the RMS feature, where the RMS is not significantly affected by lowintensity vibrations.

7.2. RMS. RMS value presents the power content in vibration and useful in detecting an imbalance in rotating machinery. According to Vishwakarma et al. [59], this is the simplest and effective technique to detect faults especially imbalance in rotating machines. However, detecting the faults at the early stage is still a problem in this method and this technique is only appropriate for the analysis of a single sinusoid waveform. The RMS value is more suitable for steady-state applications and analysis of single sinusoid waveform [1]. RMS is preferred over peak value due to the peak value's sensitivity to noise. RMS value of a pure sinusoid is equal to the area under the half-wave, which is 0.707. RMS value can be represented by

$$
\mathrm{RM}=\sqrt{\frac{1}{T} \int_{T_{1}}^{T_{2}} v(t) \mathrm{d} t}
$$

where $T$ represents time duration and $v(t)$ is the signal. Referring to Igba et al. [39], the RMS method has two disadvantages. The first one is the RMS values of a vibration signal are not affected by the isolated peaks in the signal, reducing its sensitivity towards incipient gear tooth failure. Next, it is also not significantly affected by short bursts of low-intensity vibrations. This will produce some complications in detecting the early stages of bearing failure. Bartelmus et al. [60] applied the RMS values as a diagnostic feature to diagnose gearbox fault, where the models of the behavior of gearboxes that correlate the transmission error function and load variation are presented. Sheldon et al. [61] used the RMS feature in diagnosing wind turbine gearbox and stated that applying the RMS feature is not recommended in detecting early stages of bearing failure. RMS was among the statistical parameters applied by Krishnakumari et al. [62] in fault diagnostics of the spur gear. The parameters are then combined with fuzzy logic and diagnostics accuracy was found to be $95 \%$, where DT reduces the demand for human expertise. Other applications of RMS values in vibration analysis for machine monitoring can be seen in Table $6[63,64]$.

7.3. Crest Factor. A crest factor is the ratio of the peak value of the input signal to the RMS value and is represented as follows [55]:

$$
\text { Crest Factor }=\frac{\text { peak }}{\text { RMS }}
$$

For a pure sine wave, the crest factor will be $\sqrt{2}=1.414$, and for normally distributed random noise, the value will be approximately 3. Compared to peak and RMS values, the crest factor is usually used when measurements are conducted at different rotational speeds because it is independent of speed. Crest factors are also reliable only in the presence of significant impulsiveness [1]. Jiang et al. [65] employed the crest factor features and SVM to diagnose gear faults. It was found that the crest factor is the most sensitive feature for gear failure and by applying this feature, the achieved diagnostic accuracy is $93.33 \%$. Shrivastava and Wadhwani [58] applied the crest factor values along with other time domain features for the fault detection and diagnosis of rotating electrical machines. They found that the crest factor feature is unable to classify between healthy bearing, bearing with defective ball, and bearing with defective outer race. Aiswarya et al. [66] used the crest factor feature along with other time domain features to diagnose faults in the turbo pump of a liquid rocket engine. Combined with the SVM method in the fault classification stage, the proposed method can diagnose the fault effectively with $100 \%$ accuracy.

7.4. Kurtosis. Kurtosis is a nondimensional statistical measurement of the number of outliers in distribution and in vibration analysis, it corresponds to the number of transient peaks. A high number of transient peaks and a high kurtosis value may be indicative of wear. Kurtosis is not sensitive to running speed or load, and its effectiveness is dependent on the presence of significant impulsiveness in the signal [67]. Kurtosis feature can provide the information regarding the non-Gaussianity or impulsiveness of the vibration signals $[68,69]$. In machine condition monitoring applications, kurtosis is usually preferable to crest factor but the latter is more widely used. This is because the meters that can record the crest factor value are easily available and more affordable compared to the kurtosis meter. Kurtosis was among the five parameters applied by Fu et al. [70] to be incorporated with the unsupervised AI method in diagnosing rolling bearing. Based on the results, the proposed method was found to have a sensitive reflection on fault identifications, including a slight fault. Runesson [67] employed the kurtosis along with RMS value in monitoring the condition of a mechanical press. The results demonstrated that kurtosis generally is not reliable but contains some useful information in the monitoring of the gearbox of the mechanical press machine. Other research studies that applied the kurtosis approach in vibration analysis for machine monitoring can be seen in Table $6[63,71]$.

\section{Frequency Domain Analysis}

Most real-world signals can be broken down into a combination of unique sine waves. Each sine wave will appear as a vertical line in the frequency domain, where the height and position of the line represent the amplitude and frequency, respectively. In frequency domain analysis, the amplitude is plotted against frequency and compared to the time domain, and the detection of the resonant frequency component is easier. This is one of the reasons why frequency domain methods are favorable in detecting faults in the machine [59]. Several characteristics of the signal that are not visible in the perspective of time domain can be observed using frequency domain analysis. However, frequency analysis is not suitable for signals whose frequencies vary over time. 


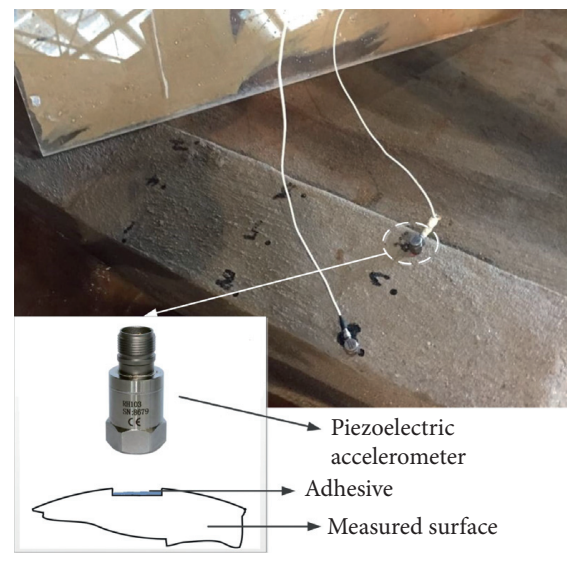

(a)

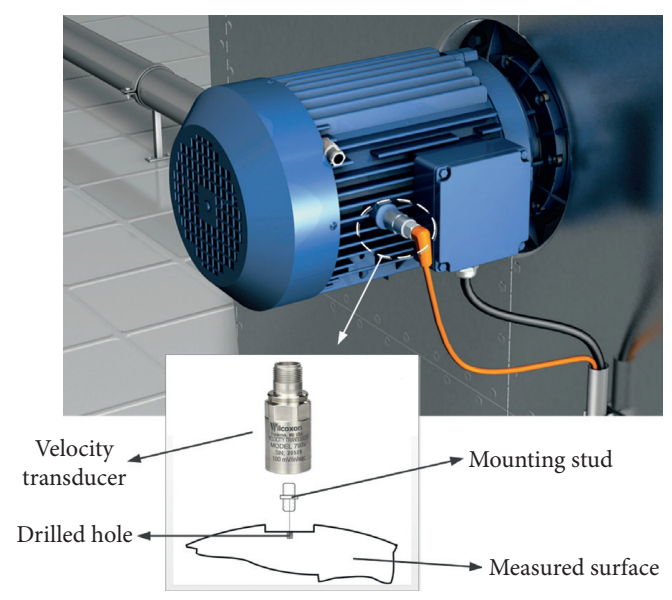

(b)

Figure 3: Vibration measurement using (a) piezoelectric accelerometer by means of adhesive mounting and (b) velocity transducer, studmounted on the machine's surface.

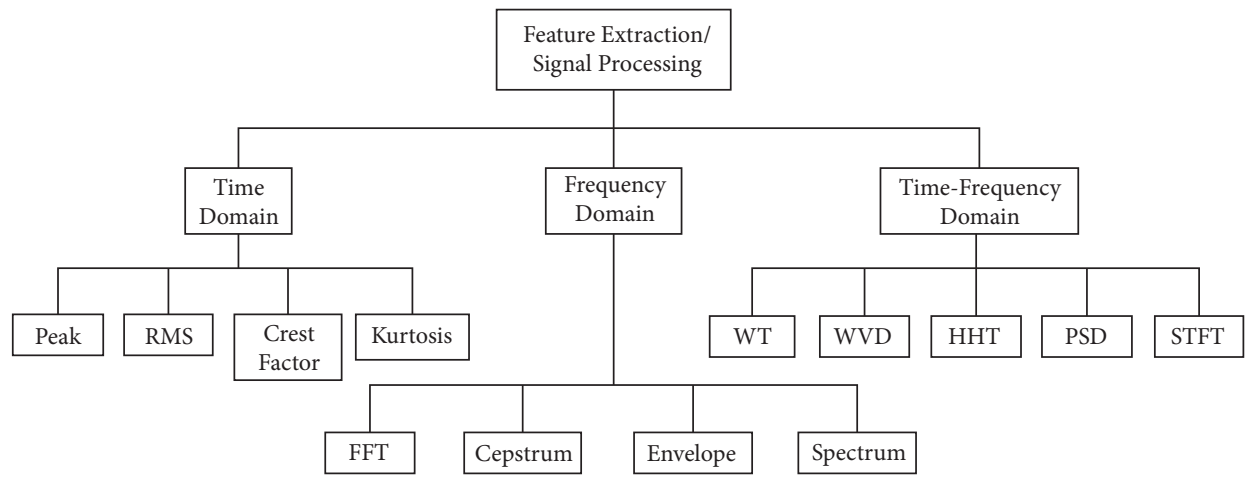

FIgURE 4: The feature extraction/signal processing stage of the proposed review article.

The advantages and disadvantages of each frequency domain method can be seen in Table 7 .

8.1. FFT. Fourier transform (FT) converts a signal $f(t)$ in the time domain to the frequency domain, generating the spectrum $F(\omega)$. FT is given by

$$
F(\omega)=F f(t)=\int_{-\infty}^{\infty} f(t) e^{-i \omega t} \mathrm{~d} t
$$

where $\omega$ is the frequency and $t$ is the time. It can be converted back to time domain from the frequency domain by inverse Fourier transform (IFT). This can be obtained as

$$
f(t)=F^{-1}(F(\omega))=\frac{1}{2 \pi} \int_{-\infty}^{\infty} F(\omega) e^{i \omega t} \mathrm{~d} \omega .
$$

FFT is an efficient and widely used algorithm to obtain the FT of discretized time signals. The FFT plot of fault-free industrial machines consists of only one peak, which represents the natural frequency of the operating machine. Thus, defect in the machine can be identified when there is a presence of other peaks aside from the natural frequency peak in the plot. However, Goyal and Pabla [37] claimed that during the conversion between domains, there is a little loss of time information. FFT is also unable to investigate the transient features efficiently in time and can predict the fault but cannot determine the severity of fault [3]. However, it is the quickest way to separate the frequencies of the signal for the diagnosis process. A combination of time domain signal analysis and FFT is normally associated with diagnosing the low-speed machine to produce more accurate results but the major concern is its reliance on the magnitude of the fault having an effect on the carrier frequency [11]. SaucedoDorantes et al. [8] used the FFT and PSD method to diagnose the fault in a gearbox and detect the bearing defect in the induction motor. They found that the proposed method can perfectly detect the presence of wear at low operating frequencies but is not suitable at high operating frequencies. Patel et al. [72] proposed the FFT method as an analysis tool in monitoring a rotating machine, and major faults such as misalignment and bearing can be monitored in this manner. Other applications of FFT can also be seen in Table $6[23,73]$.

8.2. Cepstrum Analysis. Cepstrum analysis was developed in the 1960s and can be defined as the power spectrum of the logarithm of the power spectrum [74]. Cepstrum analysis can be used to detect any periodic structure in the spectrum 
TABLE 5: The advantages and disadvantages of time domain methods.

\begin{tabular}{lcc}
\hline $\begin{array}{l}\text { Time domain } \\
\text { methods }\end{array}$ & \multicolumn{1}{c}{ Advantages } & Disadvantages \\
\hline Peak & $\begin{array}{c}\text { Simple and easy technique } \\
\text { Simple and easy technique, directly } \\
\text { related to the energy content of the } \\
\text { vibration profile }\end{array}$ & Sensitive to noise \\
Crest factor & $\begin{array}{c}\text { Easily available and affordable crest } \\
\text { factor meter }\end{array}$ & Only reliable in the presence of significant impulsiveness \\
Kurtosis & $\begin{array}{c}\text { High performance in detecting } \\
\text { periodic impulse force, highly } \\
\text { sensitive to shock, can be assimilated } \\
\text { with a shape factor, independent of } \\
\text { the signal amplitude }\end{array}$ & Costly kurtosis meter can be erroneous \\
\hline
\end{tabular}

TABLE 6: Various reported vibration analysis techniques in machine monitoring and diagnosis.

\begin{tabular}{|c|c|}
\hline Authors & Methodologies \\
\hline$[63]$ & $\begin{array}{c}\text { Incorporated the RMS and kurtosis values in NN to diagnose } \\
\text { the rolling element bearings fault }\end{array}$ \\
\hline$[71]$ & $\begin{array}{c}\text { Applied the kurtosis and SVM method to diagnose roller } \\
\text { bearing fault }\end{array}$ \\
\hline$[23]$ & $\begin{array}{l}\text { Used the FFT and PSD methods to monitor the condition of the } \\
\text { machine }\end{array}$ \\
\hline$[73]$ & Applied the FFT method to diagnose induction motor fault \\
\hline$[78]$ & $\begin{array}{l}\text { Combined the cepstrum analysis and NN method to detect and } \\
\text { diagnose gear fault }\end{array}$ \\
\hline$[79]$ & $\begin{array}{l}\text { Used two cepstrum analysis approaches, namely, automated } \\
\text { cepstrum editing procedure (ACEP) and cepstrum } \\
\text { prewhitening (CPW) to detect bearing fault }\end{array}$ \\
\hline
\end{tabular}

[81] Applied the envelope analysis to diagnose faults in rotating machines under variable speed conditions

[86] Used the envelope analysis to diagnose bearing faults

[90] Combined the higher-order spectrum analysis and SVM to diagnose faults in power electronic circuit

[91] Applied the power spectrum analysis (PSA) and SVM to diagnose rolling bearing fault

Applied the WPT method to monitor the condition of the machine

Combined the Hilbert transform and WPT to detect gearbox fault

[101] Applied a denoising method based on WT to diagnose rolling bearing and gearbox

[103] Proposed an orthonomal DWT (ODWT) method to monitor and diagnose bearing faults at an early stage

[115] Applied the HHT and FT methods to diagnose machine fault

[116] Proposed a new local mean parameter to improve the HHT method to detect gearbox fault

[120] Applied the STFT method to diagnose faults in a hydroelectric machine

The proposed method can effectively diagnose the condition using only a few features of vibration data but the fault types and severity level cannot be determined

The accuracy of the proposed method is $93.75 \%$ and can be applied even with a limited number of samples

A PC-based vibration analyzer, incorporating the proposed method was developed

The simulation results obtained from MATLAB/Simulink are in agreement with the experimental results

$\mathrm{NN}$ can diagnose gear faults with high accuracy, provided that proper measured data are used

CPW approach is more suitable for applications that do not require bandpass filtering but applying both approaches without prior knowledge can lead to false result in detecting bearing faults

Squared envelope method is an optimal approach in fault diagnosis in terms of computational cost and simplicity compared to the improved synchronous average (ISA), the cepstrum prewhitening (CPW), and the generalized synchronous average (GSA)

The squared envelope method is more suitable to analyze the cyclostationary signals compared to the envelope method

The proposed method achieved the accuracy of up to $99 \%$

Using the PSA with SVM classifier gives better result compared to NN classifier

Using the proposed method as input to a NN classifier produced nearly $100 \%$ classification accuracy. Also, the proposed method produced a better result compared to FFT when the data are corrupted by noise

The proposed method is capable of detecting early gar fault

The proposed method is more effective and has more advantages compared to Donoho's soft-thresholding denoising method

The proposed method outperforms the EEMD and Hilbert envelope spectrum analysis method

HHT outperforms FT, where FT can only differentiate characteristic frequency in low-frequency band

Introducing the new parameter improves the HHT process and makes the fault detection process simpler

The basis for the effective fault diagnosis of hydroelectric machines was proposed 
TABLE 6: Continued.

\begin{tabular}{l}
\hline Authors \\
$\begin{array}{c}\text { Methodologies } \\
{[121]}\end{array}$ \\
$\begin{array}{c}\text { Combined STFT and SVM methods to diagnose faults in } \\
\text { induction motor }\end{array}$ \\
{$[122] \quad \begin{array}{c}\text { Combined the STFT and nonnegative matrix factorization } \\
\text { (NMF) methods to detect rolling bearing element fault }\end{array}$} \\
{$[126] \quad$ Applied the PSD method to diagnose Massey Ferguson gearbox } \\
\\
{$[133] \quad$ Used the SVM method to diagnose rolling bearing element } \\
fault based on the fractal dimensions
\end{tabular}

Applied the SVM, K-nearest neighbor (KNN), and Fischer linear discriminant (FLD) methods to diagnose engine fault Presented a real-time online monitoring approach for the disc

[135] $\begin{aligned} & \text { slitting machine based on WPT and SVM methods } \\ & \text { RMS values were among the statistical features employed as }\end{aligned}$

[64] input parameters for the DNN to monitor the condition of gearbox

Compared the combination of GA with three types of $\mathrm{NN}$, namely, multilayer perceptron (MLP), radial basis function (RBF), and probabilistic neural network (PNN) to detect bearing fault

[146] Applied the combination of EMD and NN methods to diagnose the roller bearing fault

[147] Combined the WPT, GA, NN, and SVM methods to diagnose fault in diesel engine

Proposed a CNN approach that makes use of cyclic spectrum

[148] maps (CSMs) of raw vibration signal to diagnose the motor bearing in the rotating machine

Proposed a distribution-invariant deep belief network

[149] (DIDBN) as a basis for intelligent fault diagnosis of machines

[150] Used the CNN method with 1D image of raw three-axis accelerometer signal as the input

Proposed a hybrid deep signal processing method to diagnose bearing faults in the machine, where the signal processing,

feature extraction, and bearing fault diagnosis were automatically conducted

Presented the augmented deep sparse autoencoder (ADSAE)

[152] method in diagnosing gear faults, where data shifting technique was incorporated to enhance the SAE model

Combined the decision tree and fuzzy logic methods to

[62] diagnose spur gear fault based on the statistical features such as RMS, crest factor, and kurtosis

[160] Proposed the fuzzy logic method to diagnose the operation of rotating machines

[161] Applied the fuzzy logic method to monitor and diagnose the condition of the pump

[162] Proposed the combination of DWT and fuzzy logic to predict the presence of misalignment in rotating machinery

[163] Developed a gas turbine vibration monitoring approach based on Takagi-Sugeno fuzzy logic

Proposed a combination of wavelet support vector machine

[168] (WSVM) and immune genetic algorithm (IGA) to diagnose gearbox fault

Combined the GA, SVM, and EEMD methods to diagnose gear faults

Applied the combination of GA and SVM in bearing fault diagnosis

The proposed method has a huge potential to diagnose fault intelligently in other real-time system applications

The proposed method is able to determine the fault types and severity and yields $99.3 \%$ accuracy, superior to $\mathrm{NN}$

The proposed method can reliably and quickly diagnose gearbox fault

The proposed method achieved an accuracy of $98.82 \%$ and $97.16 \%$ for spur and helical gearbox dataset, respectively

SVM trained with 11 time domain statistical features and three

fractal dimensions provides better results compared to the

SVM trained with only fractal dimensions or with time domain statistical features

The performance of the SVM method is much better compared to the KNN and FLD method

Findings show that different types of disc slitting machines' faults can be successfully detected with an accuracy of $95.6 \%$

It was found that the deep learning methods are superior compared to the $\mathrm{NN}$ method, which has low robustness in diagnosing the condition of gearbox

The combination of GA with MLP and PNN gave $100 \%$ success rate whereas $\mathrm{RBF}$ gave $99.31 \%$ rate

The proposed method can successfully diagnose roller bearing fault but has an end effect complication

The proposed method produced $100 \%$ classification accuracy

Based on the validation with benchmark vibration data collected from bearing tests, the proposed technique is superior to its referenced methods in terms of the classification accuracy

The proposed method is able to achieve a high diagnosis accuracy even with new working conditions

It was found that $\mathrm{CNN}$ trained with a higher number of kernels in the first layer produced slightly better performance

The proposed method is superior to the manual extraction methods and commonly used deep learning structures in terms of accuracy, and it is not affected by the operation conditions

Compared with other deep learning architectures, the proposed method provides a higher accuracy (99\%) and only requires a few raw vibration signal data

The performance of the proposed method in diagnosing fault was found to be $95 \%$

The proposed method can easily diagnose the operational status of the rotating system

The proposed method can successfully identify and classify the faults of the five-plunger pump

The proposed approach has an error of less than $1 \%$ in predicting the degree of misalignment

Experts' knowledge regarding the maintenance of the gas turbine in accordance to the vibration level detected can be successfully expressed by the proposed method

The proposed method yielded a better diagnostic accuracy compared to the SVM and NN method, in addition to strong generalization capability

Incorporating the GA to select the parameter of SVM can improve the generalization ability and classification accuracy of the diagnostic system

Applying the cross-validation method to optimize SVM outperforms the SVM method optimized by GA in bearing fault diagnosis 
such as harmonics, sidebands, or echoes [66]. This allows faults such as bearing and localized tooth faults, which produce low-level harmonically related frequencies to be detected. There are four types of cepstrum which are real cepstrum, complex cepstrum, power spectrum, and phase spectrum, but power cepstrum is the most widely used cepstrum in machine diagnosis and monitoring. According to Goyal and Pabla [45], cepstrum analysis is important in gearbox diagnosis. Dalpiaz et al. [75] compared the cepstrum analysis with other methods in monitoring the condition of a gearbox and found that cepstrum analysis is insensitive to gear cracks. To detect the rubbing phenomenon of the sliding bearing in the machine, the cepstrum analysis method was applied by Sako et al. [76]. It was found that the proposed approach can even detect mild rubbing, which is difficult to be achieved by using conventional abnormality diagnostic methods. Experimental work was conducted by Aralikatti et al. [77] to diagnose the universal lathe machine, where cepstrum analysis was employed to the time domain signal. The vibration signal was obtained by a triaxial accelerometer. It was concluded that analyzing the vibration signal in the frequency domain does not guarantee the presence of a fault. Other applications of cepstrum analysis can be discovered in Table $6[78,79]$.

8.3. Envelope Analysis. Envelope analysis, also known as amplitude demodulation or demodulated resonance analysis, was introduced by Mechanical Technology Inc. [80]. This technique separates the low-frequency signal from background noise [59]. Envelope analysis is made up of a bandpass filtering and demodulation step that extracts the signal envelope, and its spectrum possibly contains the desired diagnostic information [81]. It is widely used in rolling element bearing and low-speed machine diagnosis and has the advantage of early detection of bearing problems $[55,81]$. The challenge of this approach is determining the best frequency band to envelope. Envelope analysis needs a sharp filter and precise specification of the frequency band for filtering in order to work smoothly [55]. Regarding bearing failure, the noise components make the envelope analysis difficult to determine the fault. The introduction of the squared envelope analysis method has solved this problem, where a squared envelope can be computed as shown in [82]. It is highly preferable in analyzing the cyclostationary signals. Rubini and Meneghetti [83] compared the envelope analysis with the wavelet transform (WT) method in diagnosing the incipient faults in ball bearings. The results demonstrated that after $30 \mathrm{~min}$ (48000 cycles), the envelope analysis is no longer able to diagnose the presence of the fault whereas the WT method is still relevant. An envelope analysis approach has also been applied by Widodo et al. [84] to preprocess the vibration signals of lowspeed bearing, and thus, determining the bearing characteristic frequencies. This method is then compared with the acoustic emission (AE) signal analysis, and during the fault recognition stage with the SVM technique, it produces worse performance than the AE approach. Envelope analysis also was applied by Leite et al. [85] to detect the bearing fault in induction motor, and the proposed method can efficiently detect fault without any information regarding the model. Application of envelope analysis in machine monitoring can also be seen in Table $6[81,86]$.

8.4. Spectrum Analysis/Comparison. Spectrum analysis is related to FFT in a way that FFT is often used in spectrum analysis to transform the signal from time to frequency domain [87]. Spectrum comparison should be conducted on a logarithmic amplitude scale $(\mathrm{dB})$ as the changes on a logarithmic axis can determine the state of the vibration. However, ones have to deal with the small fluctuations of the rotating speed of the machine [55]. A fault that is able to change the vibration signature significantly over a short period of time can be determined by this method [88]. Spectrum analysis is a complex analysis that even with the amount of literature available, expert skills are still required to exploit the diagnostic capabilities of spectrum analysis. Compared to the cepstrum analysis, spectrum analysis does not provide any information regarding the time localization of frequency component [77]. Salami et al. [38] have employed the spectrum analysis method for machine condition monitoring, and it is observed that this approach can produce smoothed and high-resolution spectral estimates of the vibration signals compared to the FFT approach. This spectral is useful for monitoring the state of machines. Ciabattoni et al. [89] proposed a novel statistical spectrum analysis (SSA) where the spectral content of vibration signals was calculated using FFT and then transformed into statistical spectral images in diagnosing faults of rotating machines. Other applications of spectrum analysis can be observed in Table $6[90,91]$.

\section{Time-Frequency Domain Analysis}

Time and frequency domains are integrated into the timefrequency domain analysis. This means that the signal frequency component and their time-variant features can be determined simultaneously in this analysis. Vibration analysis approaches mentioned before (time domain and frequency domain methods) mostly rely on the stationary assumption that is unable to detect the local features in time and frequency domain simultaneously [92]. Thus, such methods are inappropriate for nonstationary signal analysis. As mentioned before, the time-frequency domain analysis methods discussed in this study include WT, HHT, WVD, STFT, and PSD. The advantages and disadvantages of each time-frequency domain method can be seen in Table 8 .

9.1. WT. WT technique was first proposed by Morlet back in 1974 [93]. It is a linear transformation decomposing a time signal into wavelets, which are local functions of time, equipped with predetermined frequency content. Instead of sinusoidal functions, wavelets are used as the basis $[92,94]$. A suitable wavelet basis has to be chosen according to the signal structure to avoid misleading diagnosis results. WT provides a superior time localization at high frequencies compared to STFT. WT is preferable when dealing with 
TABLE 7: The advantages and disadvantages of frequency domain methods.

\begin{tabular}{|c|c|c|}
\hline $\begin{array}{l}\text { Frequency domain } \\
\text { methods }\end{array}$ & Advantages & Disadvantages \\
\hline FFT & Easy to implement, fast technique & Cannot efficiently analyze transient features in time \\
\hline Cepstrum Analysis & $\begin{array}{l}\text { Easy to implement, useful in side band } \mathrm{C} \\
\text { analysis }\end{array}$ & $\begin{array}{l}\text { Can only be applied to the well separated harmonics, the fluctuations of } \\
\text { the curve of the spectrum are averaged-out due to the filtering }\end{array}$ \\
\hline $\begin{array}{l}\text { Envelope } \\
\text { analysis }\end{array}$ & $\begin{array}{l}\text { Excellent application in bearing system, works } \\
\text { well even in the presence of a small random } \\
\text { fluctuation }\end{array}$ & Can lead to a gross diagnosis error, not suitable to be applied in the gear \\
\hline $\begin{array}{l}\text { Spectrum } \\
\text { analysis }\end{array}$ & $\begin{array}{l}\text { Useful in detecting signal that changes } \\
\text { significantly over a short period of time, higher } \\
\text { spectral estimation performance compared to } \\
\text { the FFT }\end{array}$ & Require experts' skills due to its complexity \\
\hline
\end{tabular}

nonstationary signals and in analyzing the transient signal from the measured vibration signal [95]. According to Zou and Chen [96], the WT technique is highly sensitive to stiffness variation compared to WVD. The WT method can be distinguished into discrete and continuous wavelet transform (DWT and CWT). In DWT, the power of two acts as a scaling factor, and it is typically applied through a pair of lowpass and highpass wavelet filters. The scaling factor is selected arbitrarily or via convolution for the CWT [45]. Both DWT and CWT are referred to as standard WT, which cannot efficiently perform feature extraction of certain types of signals due to its incapability to produce a sparse representation. It has a low-frequency resolution for highfrequency components and poor time localization for lowfrequency components. This gives birth to the wavelet packet transform (WPT) technique. It is a more advanced form of CWT, where it further decomposes the detailed information of the signal in the high-frequency region and improves the frequency resolution, making it applicable for the analysis of various nonstationary signals. Dalpiaz and Rivola [94] applied the WT method in monitoring the condition of the automatic packaging machine and found that WT is able to determine the variation of vibration frequency content within the machine cycle. The advantage of CWT is that it has a finer scale parameter compared to the DWT method, but in terms of computational, DWT is more efficient [97]. Al-Badour et al. [98] employed the CWT and WPT in detecting faults in rotating machinery. WPT is actually an extension of the DWT method but with finer frequency resolution. They found that in terms of speed and spectral characterization of the vibration signal, the WPT method is better than the CWT method. Rangel-Magdaleno et al. [99] applied the DWT method to detect the incipient broken bar in the induction motor, and the detection accuracies achieved are $96.55 \%$ for the unload conditions, $80.5 \%$ for the half-load, and $87.6 \%$ for the full-load condition. Other applications of the WT technique can be found in Table 6 [100-103].

9.2. WVD. Wigner introduced the WVD method and Ville applied it to process the signal, and thus, it was named the Wigner-Ville distribution. It is a specific case of the Cohen class distributions which yields a time-frequency energy density computed by correlating the signal with a time and frequency translation of itself [104]. The WVD of a signal $x(t)$ is represented aswhere $x^{*}$ is the conjugate of $x$ and $\tau$ is the delay variable. WVD has several advantages such as better resolution than STFT, excellent accuracy, and window function is not needed for its analysis [45]. WVD is not directly used by researchers to determine the time-frequency structures of signals because of the cross-term interference problem [93].

$$
W_{X}(t, \omega)=\frac{1}{2 \pi} \int_{-\infty}^{+\infty} x\left(t+\frac{\tau}{2}\right) \cdot x^{*}\left(t-\frac{\tau}{2}\right) \cdot e^{-j \tau \omega} \mathrm{d} \tau,
$$

Staszewski et al. [105] performed the fault detection analysis on the gearbox using the original WVD method and its weighted form, and they claimed that compared to the original WVD, its weighted form can reduce interference in the time-frequency domain, with a cost of a reduction in the frequency resolution. Directional Wigner distribution (dWD) was specifically developed for transient complexvalued signal analysis and applied in rotating or reciprocating machines by [106]. Baydar and Ball [107] used the smooth pseudo WVD technique on acoustic and vibration signals to diagnose the gearbox condition, and the results showed that acoustic signals were more effective in early fault detection, compared to vibration signals. An application of the WVD method in diagnosing induction machines was demonstrated by Climente-Alarcon et al. [104]. By using this proposed technique, more reliable diagnosis results might be obtained in a situation where harmonics tracing is difficult.

9.3. HHT. David Hilbert first introduced the Hilbert transform in 1905. Then, Huang et al. [108] introduced the HHT in 1998 to determine the characteristics of stationary, nonstationary, and transient signals. HHT consists of empirical mode decomposition (EMD) of signals and Hilbert transform, and by combining these two methods, a Hilbert spectrum can be obtained, where the faults in a running machine can be diagnosed [92]. Thus, in this manuscript, any works regarding the EMD method fall into the HHT section. A complicated multicomponent signal can be broken down into a series of intrinsic mode functions (IMFs) using this method. By using the EMD technique, a complicated signal $x(t)$ can be reconstructed with the help of IMFs, expressed as 
TABLE 8: The advantages and disadvantages of time-frequency domain methods.

\begin{tabular}{|c|c|c|}
\hline $\begin{array}{l}\text { Time-frequency } \\
\text { domain methods }\end{array}$ & Advantages & Disadvantages \\
\hline WT & $\begin{array}{l}\text { Provide a superior time localization at high frequencies } \\
\text { compared to STFT, more flexible compared to STFT, } \\
\text { availability of various wavelet functions }\end{array}$ & $\begin{array}{l}\text { Suffers from the convolution of a priori basis functions } \\
\text { with the original signal, difficult to choose the mother } \\
\text { wavelet type }\end{array}$ \\
\hline WVD & $\begin{array}{c}\text { Has a good time and frequency resolution, does not require } \\
\text { window function for its implementation }\end{array}$ & Vulnerable to interference, slower than STFT \\
\hline HНT & $\begin{array}{c}\text { Has a good time and frequency resolution, does not require } \\
\text { priori basis functions }\end{array}$ & $\begin{array}{l}\text { Result misinterpretation due to IMFs generated at the } \\
\text { low-frequency region }\end{array}$ \\
\hline STFT & $\begin{array}{c}\text { Straightforward method and recommended for beginners } \\
\text { in the time-frequency analysis, low computational } \\
\text { complexity }\end{array}$ & $\begin{array}{l}\text { Constant frequency resolution for the whole signal, } \\
\text { difficult to find a fast and effective algorithm to calculate } \\
\text { STFT }\end{array}$ \\
\hline PSD & $\begin{array}{c}\text { Can be directly computed by FFT, requires very little } \\
\text { processing power }\end{array}$ & Frequency resolution is affected by the window size \\
\hline
\end{tabular}

$$
x(t)=\int_{-\infty}^{\infty} c_{i}(t)+r_{n}(t) \mathrm{d} t
$$

where $c_{i}(t)$ is the th IMF and $x_{n}(t)$ is the residual signal that represents the slowly varying or constant trend of the signal [92]. HHT has several advantages such as low computational time, and it does not associate with any convolution [45]. However, EMD, which is the main part of HHT, has certain drawbacks. People might misinterpret the result due to unenviable IMFs generated at the low-frequency region, and in addition to that, the lowfrequency components' signals cannot be separated. Thus, the ensemble EMD (EEMD) method was introduced to overcome the limitation of EMD by introducing Gaussian white noise to the EMD $[92,109]$. However, in the lowfrequency region, the energy leakage and modal aliasing problems still exist. This is what motivates Torres et al. [110] to propose the complete EEMD with adaptive noise (CEEMDAN) method, which can produce better modal frequency spectrum separation outputs.

Peng et al. [111] introduced a better version of HHT that incorporated the WPT technique to decompose the vibration signal into a set of narrowband signals. The proposed method was shown to have a better resolution in the time and frequency domain compared to the waveletbased scalogram. Wu et al. [112] employed the HHT approach in diagnosing the looseness faults of rotating machinery, and the proposed technique is successful in determining the faults at different components of the machine. Osman and Wang [113] proposed a normalized HHT (NHHT) technique to tackle the problem of selecting the appropriate distinctive IMF components, especially for bearing health condition monitoring. However, the EMD of the proposed method only processes signals over narrowbands. Chen et al. [114] proposed a combination of CEEMDAN and particle swarm optimization least squares support vector machine (PSOLSSVM) to improve the diagnosis accuracy of rolling bearings. The diagnosis accuracy of several rolling bearings fault types was improved by this method to $100 \%$. Other applications of HHT in machine monitoring and diagnosis can be observed in Table $6[115,116]$.
9.4. STFT. STFT was pioneered by Gabor back in 1946 in the communication field [117]. It has the ability to counter the limitations of FFT and is mostly applied to extract the narrowband frequency content in nonstationary or noisy signals [37]. In the STFT method, the initial vibration signal is broken down into time segments by windowing, and then FT is applied to each time segment [45]. The mathematical equation for STFT is given by

$$
\operatorname{STFT}(f, \tau)=\int_{-\infty}^{\infty} x(t) \omega(t-\tau) e^{-j 2 \pi f t} \mathrm{~d} t,
$$

where $x(t)$ is the interpreted signal and $\omega(t)$ is the window function centered at time T. STFT depends on the width of the window. AA large window width is chosen to obtain greater accuracy in frequency, whereas to improve the accuracy in time, a small window width is desired. The main drawback of this approach is that it cannot achieve high resolution in the time and frequency domain simultaneously.

Safizadeh et al. [118] proposed the STFT application in machinery diagnosis and proved that although STFT provides the time-frequency information with limited precision, and it is better than the conventional methods of machine diagnosis. To avoid cross-term effects, Burriel-Valencia et al. [119] implemented the STFT method for fault diagnosis of induction machines, where the spectrums in the frequency domain in the relevant frequency band are filtered. The proposed method greatly reduced the computing time and memory resources. The STFT method has also been applied in fault diagnosis of hydroelectric machine [120], induction motor [121], and rolling element bearing [122] (refer to Table 6).

9.5. PSD. PSD can be applied to measure the amplitude of oscillatory signals in the time series data and determine the energy strength of frequencies, which may be useful for further analysis. From the complex spectrum, the one-sided PSD can be computed in $\left(\mathrm{m} / \mathrm{s}^{2}\right)^{2} / \mathrm{Hz}$ as

$$
\operatorname{PSD}(f)=\frac{2|X(f)|^{2}}{\left(t_{2}-t_{1}\right)},
$$


where $t_{2}-t_{1}$ is the time range and $X(f)$ is the complex spectrum of the vibration $x(t)$ in a time range, which can be expressed in units of $\left(\mathrm{m} / \mathrm{s}^{2} / \mathrm{Hz}\right)$. PSD can also be directly calculated in the frequency domain if FFT of vibration signal is used, by applying the following formula [123]:

$$
\mathrm{PSD}=\frac{\left(G_{\mathrm{rms}}\right)^{2}}{f},
$$

where $G_{\text {rms }}$ is the root-mean-square of acceleration in a certain frequency $f$. PSD can analyze the faulty frequency bands without facing a slip variation issue and does not necessarily focus on one specific harmonic [124]. It requires very little processing power and can be directly computed by FFT or by converting the autocorrelation function [45].

PSD technique has been used by Cusido et al. [124] alongside WT to diagnose faults in induction machines, and the proposed technique can successfully diagnose faults for every operating point of the induction motor. However, to improve the diagnosis accuracy, good knowledge to determine the suitable mother wavelet and sampling frequencies are still required. Mollazade et al. [123] also used the PSD values in the feature extraction stage and fuzzy logic in the fault recognition stage of fault diagnosis of hydraulic pumps. The classification accuracy of the proposed technique for 1000,1500 , and $2000 \mathrm{rpm}$ conditions is $96.42 \%, 100 \%$, and $96.42 \%$, respectively. Other applications of PSD in machine monitoring and diagnosis can be seen in Table $6[125,126]$.

\section{Fault Recognition/AI-Based Technique (RQ 3)}

The application of AI in vibration analysis for machine monitoring and diagnosis has become increasingly popular, and based on this review, AI-based techniques contribute about $57 \%$ of the overall vibration analysis method in machine diagnosis and monitoring, as shown in Figure 5.

This is because most of the techniques mentioned before require huge expertise for successful implementation, which makes them not suitable for common users [80]. Furthermore, the expert is not immediately available. This is where AI-based methods come in because a nonexpert user can make reliable decisions without the presence of a machine diagnosis expert. AI can be defined as any task performed by a program or a machine that is difficult enough that it requires intelligence to accomplish it [127]. Several AI-based methods of vibration analysis for machine monitoring and diagnosis are SVM, NN, fuzzy logic, and GA.

10.1. SVM. SVM was initially introduced by Vapnik and is the most widely used classification algorithm. This method transforms the data set or sample space to a high-dimensional, kernel-induced feature space by nonlinear transformation and then determines the best hyperplane [1]. The best hyperplane means the one with the largest margin between the two classes A and B, as shown in Figure 6. The data points from both classes that are closer to the hyperplane and influence the position and orientation of the hyperplane are called support vectors.
The learning and test data for the SVM are obtained from the feature extraction process and after training the SVM algorithm, the SVM matrix was obtained [128]. Optimization methods such as GA and particle swarm optimization (PSO) are usually incorporated with SVM in order to achieve better results. One of the reasons why SVM is widely applied in vibration analysis for machine diagnosis is due to its compatibility with large and complex datasets such as data collected in the manufacturing industry [129]. SVM is very useful as the number of features of classified entities will not affect the performance of SVM [130]. This means that for the base of the diagnosis system, there is no limited number of attributes that can be selected. There is no requirement for experts' knowledge in SVM, as is the case with fuzzy logic, and no layers are involved in SVM structure, compared to NN.

Poyhonen et al. [130] implemented the SVM technique to diagnose faults in an electrical machine, and the results showed that the classification accuracy was high, except for the detection of eccentric rotors. Tabrizi et al. [131] combined the SVM with the WPT (for signal preprocessing) and EEMD (for feature extraction) methods to detect small defects on roller bearings under different operating conditions. A classification tree kernel-based SVM has also been employed together with CWT to identify bearing faults, and this combination proves to be a promising method and superior to other SVM methods with common kernels in diagnosing the rolling element bearing fault [132]. Pinheiro et al. [128] used the SVM method for fault diagnosis of a rotary machine and successfully detected several unbalance faults. However, its performance is still questionable as a small number of samples are used. Further implementation of SVM in vibration analysis for machine diagnosis can be found in Table 6 [90, 133-135].

10.2. NN. NN is made up of a large number of richly interconnected artificial processing neurons called nodes, connected to each other in layers forming a network [136]. $\mathrm{NN}$ has the ability to model processes and systems from raw vibration data extracted from frequency and time-frequency domain techniques mentioned before [137]. In the training stage of $\mathrm{NN}$, superior input variables might suppress the influence of the weak variables. Thus, the data must be properly processed and scaled before being fed into the $\mathrm{NN}$. Normalizing the raw vibration data to the values between 0 and 1 can help to reduce the effect of the input variable [137]. Training time increases according to the complexity of the network, and this directly affects the accuracy of the results. Due to the robustness and efficiency in handling noisy data, the backpropagation neural network (BPNN) is widely used in machine diagnosis [138]. BPNN, pioneered by Rumelhart and McClelland in 1986, is made up of three layers, which are input, hidden, and output layer [93]. The presence of hidden layers gives the $\mathrm{NN}$ an ability to explain nonlinear systems, and the higher the number of hidden layers, the deeper the NN [139]. Similar to the SVM method, NN does not need a knowledge base to detect the location of the faults, unlike the fuzzy logic method. Ertunc et al. [140] compared 


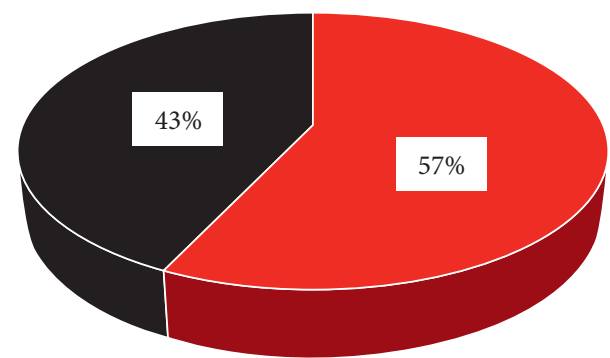

AI-Method

- Non AI-Method

Figure 5: The percentage difference between AI and non-AI methods in vibration analysis for machine diagnosis and monitoring.

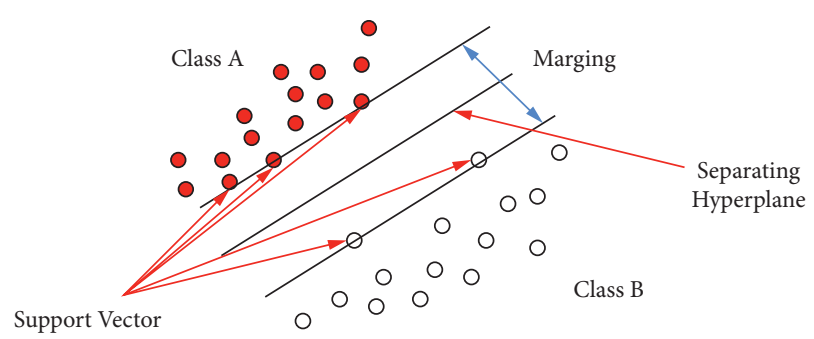

Figure 6: The structure of SVM technique.

the performance of $\mathrm{NN}$ and the combination of $\mathrm{NN}$ and fuzzy logic, which is known as adaptive neurofuzzy inference systems (ANFIS). Envelope analysis was applied for the signal processing step. They concluded that the ANFIS method was superior to the NN, especially in diagnosing fault severity. Castelino et al. [137] used the application of $\mathrm{NN}$ in the vibration monitoring carried out on industrial rotary machines that were running in real operating conditions. The results showed that NN performed better for nonstationary signals in the time-frequency domain compared to the frequency domain. Recently, the deep learning or deep neural network (DNN) has been applied widely in machine monitoring and diagnosis. It is a type of $\mathrm{NN}$ that contains more than one hidden layer. Compared to the $\mathrm{NN}$ and SVM method, the DNN approach can adaptively learn the hierarchical representation from raw data through multiple nonlinear transformations and approximate complex nonlinear functions instead of extracting the fault feature manually [141]. However, due to its deep architecture, a high number of parameters are involved, which leads to the risk of overfitting. Widely applied DNN architectures include autoencoders (AE), convolutional neural network $(\mathrm{CNN})$, restricted Boltzmann machines, and deep belief networks. Table 9 shows the comparison between NN and deep learning/DNN in machine monitoring and diagnosis.

Hoang and Kang [142] applied the CNN technique, which is a class of DNN that is most commonly applied for image analysis, to diagnose the rolling element bearing in rotary machines. Raw vibration signals in time domain are converted into a $2 \mathrm{D}$ form for the $\mathrm{CNN}$ to perform vibration image classification. This method achieved 100\% accuracy using the bearing datasets from Case Western Reverse University, but hyperparameters for the CNN model can still be improved. A combination of transfer learning and DNN has been employed by Qian et al. [143] in diagnosing the rotating machines under different working conditions. Transfer learning focuses on how to store the knowledge or solution obtained when solving a problem and apply it to different but related problems so that the amount of data collection and training costs can be reduced [144]. The proposed method is robust, and there is no requirement for further training when supplied with new datasets from different working conditions. Similar applications can also be found in Table $6[78,145-152]$.

10.3. Fuzzy Logic. Compared to conventional logic, fuzzy logic aims at modeling the imprecise modes of reasoning to make rational decisions in an environment of uncertainty and imprecision $[153,154]$. There are four main stages of the fuzzy logic system, which are fuzzification, an inference mechanism, rule-base, and defuzzification component. The fuzzification stage converts the input data into fuzzy sets before the fuzzy inference stage makes a reliable conclusion based on the rules created in the rule-base stage. Finally, the defuzzification stage produces quantifiable results. Fuzzy logic is associated with membership functions, which role is to map the nonfuzzy input values to fuzzy linguistic terms and vice versa. To obtain a diagnostic system with excellent sensitivity, the rules and membership functions can be tuned [155]. However, properly determine the fuzzy rules and optimize the membership functions are the biggest challenge in fuzzy logic. Fuzzy logic is easier to implement compared to SVM and NN. Apart from that, unlike other AI methods such as SVM and NN, it does not rely on the datasets as there is no training or testing stage in fuzzy logic. In particular cases, this method can only provide a general diagnosis, as the specific fault symptom of a machine cannot be regularly determined. However, this is the only available alternative when collecting the fault data is not possible [156]. Lasurt et al. [157] compared the performance of fuzzy logic with $\mathrm{NN}$ in fault diagnosis of electrical machines, and they claimed that fuzzy logic performs better in detecting different faults for a wide range of operating conditions, compared to NN. Wu and Hsu [158] combined the method of DWT and fuzzy logic to detect gear fault and the results obtained showed that the recognition rate of the proposed method is over $96 \%$ under various experimental conditions. Mukane et al. [159] applied the FFT method for signal processing and fuzzy logic for fault recognition in identifying machinery faults. Multiple faults can be identified in this manner including the severity of the faults. Other applications of fuzzy logic in vibration analysis for machine diagnosis can be found in Table 6 [160-163].

10.4. GA. GA, derived from a study of a biological system, can solve both constrained and unconstrained optimization problems based on a natural selection process $[164,165]$. At each step, GA randomly selects the best individuals based on their quality from the current population to become parents for the children of the next 
TABle 9: NN vs. deep learning/DNN.

\begin{tabular}{lcc}
\hline Characteristics & NN & Deep learning/DNN \\
\hline Prior knowledge & Required & Not required \\
Computational burden & Lower & Higher \\
Feature extraction & Manual & Automated \\
Accuracy & Lower & Higher \\
Robustness & Lower & Higher \\
\hline
\end{tabular}

generation, in order to reach an optimal solution. This step will continue until a terminating condition is reached. There are three main processes that occur at each GA, namely, selection, crossover, and mutation. GA is usually used to optimize the monitoring system parameters and boosting the speed and accuracy of fault diagnosis. Samanta et al. [145] presented a combination of ANN and SVM with GA for bearing fault detection. Based on the result, SVM performs better than $\mathrm{NN}$, and GA helps to reduce the training time of both methods. Han et al. [166] used the GA in the process of diagnosing the induction motor and found that GA helps the diagnosis system to perform better by choosing critical features and optimizing the network structure. Hajnayeb et al. [167] claimed that removing some features from the input features will result in quicker and more accurate diagnosis systems. GA is usually combined with other AI methods such as SVM, fuzzy logic, and $\mathrm{NN}$. In $\mathrm{NN}$, the GA can be used as an alternative to learning the weight values and to optimize the topology of a $\mathrm{NN}$. For the fuzzy control, the GA can be used to tune the associated membership function parameters as well as generating the fuzzy rules. The applications of GA can also be observed in Table 6 [168-170]. The advantages and disadvantages of each fault recognition method can be seen in Table 10.

\section{Discussion}

More than 100 articles were discussed in this study, covering a topic associated with the vibration analysis in machine monitoring and diagnosis in terms of instruments used in the data acquisition stage, feature extraction methods, and fault recognition by AI techniques. Because there is a large amount of literature on this field, a review of all the literature is impossible, and some papers might be omitted. For the data acquisition process and to answer the RQ 1 , most of the studies applied the simpler and cheaper alternative of the computer-based analyzer, and with the help of DSP and FPGA, this analyzer is nearly as good as the conventional analyzer. Accelerometer is still the best sensor option for vibration analysis, and this has been proved by most of the articles reviewed. However, due to the high cost of the piezoelectric accelerometer, researchers are continuously working towards the application of the MEMS accelerometer, which can provide the same or better performance. Velocity transducer is preferable to be applied in diagnosing low-speed machinery compared to accelerometers as the absolute accelerations measured are much smaller in value for similar vibration displacements. Noncontact sensors also have a huge potential in machine monitoring as mounting the sensor on the machine is not a concern anymore which in turn, produces a more accurate measurement. However, due to its costly application, it is not widely used. LDV with multichannel measurements is expected to be widely applied in the future, where the cost of implementing the LDV is reduced.

Regarding the signal processing techniques (RQ 2), the works on improving the detection and diagnosis of faults in the time-frequency domain have attracted numerous attention from researchers. This is because it can be implemented to investigate the nonstationary signals as failure signals are not repetitive at the earliest stage. Usually, these nonstationary signals contain abundant information on machine faults. Time and frequency domain techniques for machine monitoring are based on the assumption of stationary signals, and this is not suitable for detecting shortduration dynamic phenomena, especially in rotating machinery. However, traditional methods should not be omitted as it is preferable in certain applications. For lowspeed machines, envelope analysis is widely applied as it can detect low energy signals and the envelope spectrum is further analyzed using time-frequency domain methods such as WT and HHT, where the noise level in the vibration signals is reduced. To make use of the advantages of a certain method and to make up for the limitations, some researchers applied the fusion of certain techniques. Based on Figures $7(a)-7(c)$, the most applied time, frequency, and time-frequency domain methods in machine monitoring and diagnosis are RMS, FFT, and WT techniques, respectively.

To answer the RQ 3, researchers also move towards implementing the intelligence system in the vibration analysis for automated decision making, and from the review and referring to Figure 7(d), SVM is the most widely used method mainly due to its high classification accuracy and low computational time. Besides, it was found that the application of the time domain parameters is directly proportional to the applications of AI methods. This is because time domain features can improve the performance of AI methods and have a low computational cost, which would not put much computational burden on AI methods. The works on refining the algorithms for lower computational cost and easy implementation of the vibration analysis are still in progress for the AI-based techniques. Based on the previous studies regarding vibration analysis for machine monitoring and diagnosis, most of the reported studies applied the vibration analysis method on one test rig or machine, where the results produced are excellent but the same performance cannot be guaranteed when applied to other machines. This also applies to the environment, where most of the reported works are conducted in a controlled environment and the performance might differ if employed in an industrial setting. Similar cases applied to the fault recognition using AI, especially in SVM and NN methods. These data-driven methods are based on the training of historically obtained datasets fed to the algorithm, and when entirely new datasets are used, generalization issues might occur. Thus, it is important to train the AI algorithms with appropriate, diverse, and optimized datasets. It is also recommended to 
TABLE 10: The advantages and disadvantages several AI-based methods.

\begin{tabular}{|c|c|c|}
\hline $\begin{array}{l}\text { AI-based } \\
\text { method }\end{array}$ & Advantages & Disadvantages \\
\hline SVM & $\begin{array}{l}\text { Compatible with large and complex dataset, high } \\
\text { accuracy }\end{array}$ & $\begin{array}{l}\text { Difficult to determine the appropriate kernel to be applied, } \\
\text { perform poorly when the data contain noise }\end{array}$ \\
\hline $\mathrm{NN}$ & $\begin{array}{l}\text { Fault tolerance process, have a self-learning ability Have } \\
\text { a strong capability to process data }\end{array}$ & $\begin{array}{c}\text { Complicated design process, takes a long time to process a large } \\
\text { network, black box solution }\end{array}$ \\
\hline Fuzzy logic & Strong robustness, simple design and easy to understand & $\begin{array}{l}\text { Difficult to obtain the knowledge rules, difficult to determine the } \\
\text { right membership function }\end{array}$ \\
\hline GA & $\begin{array}{l}\text { Can process an extremely large range of data, can be } \\
\text { applied for the optimization purpose }\end{array}$ & High computing cost, time-consuming procedure \\
\hline
\end{tabular}

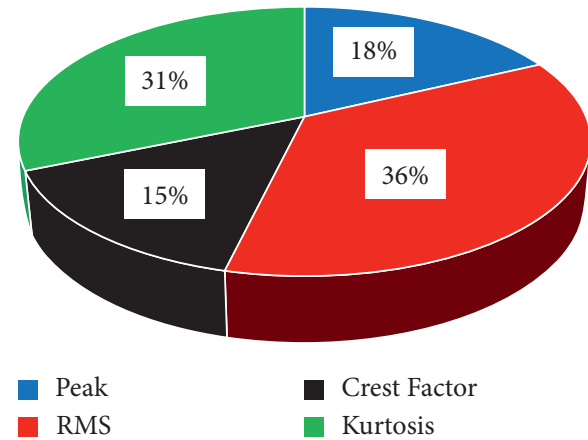

(a)

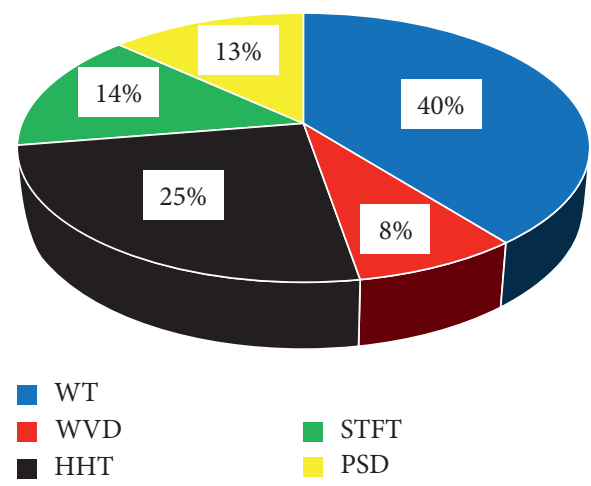

(c)

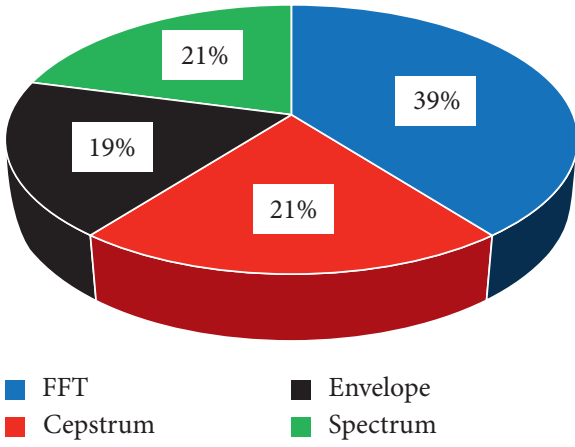

(b)

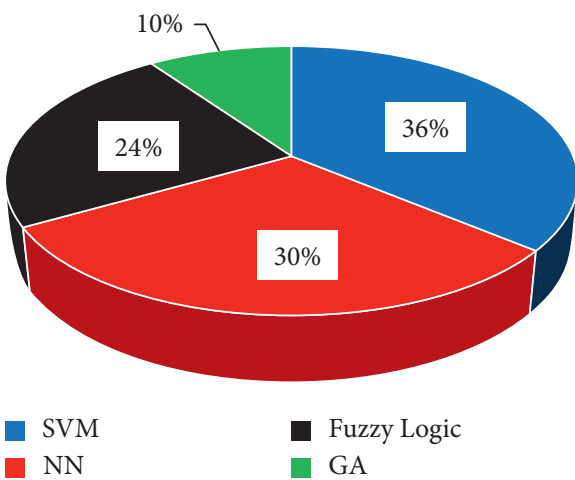

(d)

Figure 7: Percentage of methods used for (a) time domain, (b) frequency domain, (c) time-frequency domain, and (d) AI-based approaches, based on the reported articles.

test the AI techniques at different operating or environmental conditions than the training datasets to counter the generalization problem. It was discovered that almost $80 \%$ of the previous studies applied the feature extraction or signal processing techniques such as envelope analysis, STFT, WT, and HHT, whether with the combination of AI method or not. Although these techniques achieved good performance in monitoring and diagnosing the machine condition, expert knowledge regarding signal processing is still required. Furthermore, the feature extractor has to be reconstructed for every specific fault diagnosis task. This is one of the reasons researchers are migrating to the deep learning approach where fault features are automatically extracted from the raw vibration signals.
In terms of noise, most of the reported existing methods can effectively distinguish noise from vibration signals. However, this is based on the assumption of Gaussian distribution vibration signals. In an industrial environment, vibration signals are usually corrupted with non-Gaussian noise, due to the abnormal operation of gears or bearings and random disturbances that occur in the machine, which is not widely considered in the reported techniques. This is because industrial machines are complex systems made up of various components such as shafts, bearings, and gearboxes, which run simultaneously. Thus, some fault signatures are often covered by the machine natural frequencies and submerged by high non-Gaussian noise, and as a result, the faulty frequencies 
TABLE 11: The most influencing articles for each methods.

\begin{tabular}{lcc}
\hline Methods & Articles's name & $\begin{array}{c}\text { Number } \\
\text { of citation }\end{array}$ \\
Time domain & $\begin{array}{c}\text { Fault diagnostics of rolling element bearing using the NN method and the time domain features of RMS } \\
\text { and kurtosis conducted by [63]. From the results, the proposed method can still effectively diagnose the } \\
\text { machine even with the reduced number of inputs. }\end{array}$ \\
$\begin{array}{l}\text { Frequency domain } \\
\text { A research conducted by [86] to study the relationship between the classical envelope analysis and } \\
\text { spectral correlation analysis in the diagnostics of bearing faults. It was shown that the envelope analysis } \\
\text { provided the same results as the complex spectral correlation function. }\end{array}$ \\
$\begin{array}{l}\text { Time-frequency } \\
\text { domain }\end{array}$ \\
$\begin{array}{c}\text { A study on applying the CWT method in the feature extraction of mechanical vibration signals } \\
\text { conducted by [101]. The results proved that the proposed method is more effective than the Donoho's } \\
\text { "soft-thresholding denoising" method. } \\
\text { Similar to [63]. }\end{array}$
\end{tabular}

become nondominant in the spectrum, which makes the machine diagnosis and monitoring process more difficult [171, 172].

For RQ 4, recent applications of smart machines present a new and huge challenge in monitoring and diagnosing their condition. The presence of various sensors and communication devices in the smart machine will produce very noisy data. Thus, research studies on a vibration technique that is precise and robust and can handle a huge amount of noisy data efficiently are desired. Sometimes the collected vibration data from the sensors are insufficient for machine diagnosis and monitoring. This is why the need for the Digital Twin modeling approach arises. According to [173, 174], the Digital Twin model can map various characteristics of the physical machine into the virtual world to produce a digital replica of the machine that is transferable, detachable, modifiable, reproducible, repeatable, and erasable. Thus, extrapolating the vibration data acquired from the sensors is possible based on the mathematical representation of the machine. By combining the AIbased data-driven approach and physics-based simulation model, Digital Twin can obtain additional information regarding the prediction of machine failures. This model can also be applied to run several simulations in different operational and environmental conditions, increasing the robustness of the diagnosis technique. However, producing an effective and proper Digital Twin model remains a challenge due to the nonlinear dynamics, and uncertainty that occurs in the operating smart machines [175]. Thus, works on constructing a Digital Twin model that can properly represent the actual conditions of the machine still can be explored. In addition, a technique to monitor and diagnose the machine's condition from a remote location without the need to visit the machine is worth exploring. For AI-based techniques, the performance can be further evaluated by studying the effects of simultaneous fault occurrence on the machine. In terms of AI algorithms, incorporating the transfer learning approach into the algorithm can be further explored since the deep transfer learning method is still in its early stages. Table 11 shows the most cited articles reviewed in this manuscript for each method to answer the RQ 5.

\section{Conclusion}

Vibration analysis for machine monitoring and diagnosis has become cheaper and cheaper thanks to the emerging technology and development in the data acquisition process and signal processing techniques including the instrument applied. Nowadays, even inexperienced users can conduct effective vibration monitoring without the presence of an expert. In this study, we have conduct a systematic review of vibration analysis for machine monitoring and diagnosis, which can be divided into data acquisition, feature extraction, and fault recognition stages. Several RQs have been answered in this study which might provide useful information on this area. From the study, several key factors are determined:

(i) With the advancement of powerful software and the Internet, a computer-based analyzer is preferable in the future due to its low cost and performance, which is as good as the standalone analyzer.

(ii) Noncontact sensor is the future of vibration analysis for machine monitoring and diagnosis due to its flexibility and independence of any mass-loading effects, without compromising the signal quality.

(iii) Time and frequency domain methods are suitable for stationary signals and time-frequency domain techniques are preferable for nonstationary signals and early fault detection.

(iv) Deep learning, especially the deep transfer learning method, is starting to be applied in vibration analysis for machine monitoring and diagnosis as it helps in minimizing the requirement for expert knowledge in the complicated feature extraction step. Traditional AI methods such as SVM, NN, and fuzzy logic still require expert knowledge in the feature extraction stage of newly fed datasets.

(v) Traditional time domain features such as RMS and crest factor are still relevant in the future and its application with AI will continue to increase.

\section{Data Availability}

The data used to support the findings of this study are available from the corresponding author upon request.

\section{Conflicts of Interest}

The authors declare no conflicts of interest. 


\section{Acknowledgments}

The authors would like to thank Synvue Sdn Bhd (1236749D) for insights and feedback of the project development. This work was supported by the Collaborative Research in Engineering, Science, and Technology (CREST) under grant 304/PELECT/6050424/C121.

\section{References}

[1] A. Aherwar and M. S. Khalid, "Vibration analysis techniques for gearbox diagnostic: a review," International Journal of Advances in Engineering \& Technology, vol. 3, no. 2, pp. 4-12, 2012.

[2] D. H. C. de Sá Só, D. P. Viana, A. A. de Lima et al., "Diagnostic and severity analysis of combined failures composed by imbalance and misalignment in rotating machines," International Journal of Advanced Manufacturing Technology, vol. 114, no. 9, pp. 3077-3092, 2021.

[3] S. Kumar, M. Lokesha, K. Kumar, and K. Srinivas, "Vibration based fault diagnosis techniques for rotating mechanical components: review paper," in Proceedings of the International Conference on Advances in Manufacturing, Materials and Energy Engineering, pp. 1-6, Karnataka, India, June 2018.

[4] R. Ranjan, S. K. Ghosh, and M. Kumar, "Fault diagnosis of journal bearing in a hydropower plant using wear debris, vibration and temperature analysis: a case study," Proceedings of the Institution of Mechanical Engineers - Part E: Journal of Process Mechanical Engineering, vol. 234, no. 3, pp. 235-242, 2020.

[5] A. Glowacz, "Ventilation diagnosis of angle grinder using thermal imaging," Sensors, vol. 21, no. 8, p. 2853, 2021.

[6] A. Glowacz, R. Tadeusiewicz, S. Legutko et al., "Fault diagnosis of angle grinders and electric impact drills using acoustic signals," Applied Acoustics, vol. 179, p. 108070, 2021.

[7] D. N. Brown and T. Jensen, "Machine-condition monitoring using vibration analysis," 2020, https://www.bksv.com/ media/doc/bo0253.pdfAvailable:.

[8] J. J. Saucedo-Dorantes, M. Delgado-Prieto, J. A. OrtegaRedondo, R. A. Osornio-Rios, and R. D. J. Romero-Troncoso, "Multiple-fault detection methodology based on vibration and current analysis applied to bearings in induction motors and gearboxes on the kinematic chain," Shock and Vibration, vol. 2016, Article ID 5467643, 13 pages, 2016.

[9] W.-B. Zoungrana, A. Chehri, and A. Zimmermann, "Automatic classification of rotating machinery defects using machine learning (ml) algorithms," Human Centred Intelligent Systems, vol. 189, pp. 193-203, 2020.

[10] S. Elango, J. G. Aravind, and S. Boopathi, "Vibration analysis of bearing by using mechanical stethoscope," International Journal of Advanced Science and Research, vol. 3, no. 1, pp. 1137-1149, 2018.

[11] Y. H. Kim, A. C. C. Tan, and V. Kosse, "Condition monitoring of low-speed bearings - a review," Australian Journal of Mechanical Engineering, vol. 6, no. 1, pp. 61-68, 2008.

[12] M. Vishwakarma, R. Purohit, V. Harshlata, and P. Rajput, "Vibration analysis \& condition monitoring for rotating machines: a review," in Proceedings of the 5th International Conference of Materials Processing and Characterization, pp. 2659-2664, Elsevier, Hyderabad, India, March 2016.

[13] A. Boudiaf, A. Djebala, H. Bendjma, A. Balaska, and A. Dahane, "A summary of vibration analysis techniques for fault detection and diagnosis in bearing," in Proceedings of the 8th International Conference on Modelling, Identification and Control (ICMIC), pp. 37-42, Algiers, Algeria, November 2016.

[14] A. Aherwar, "An investigation on gearbox fault detection using vibration analysis techniques: a review," Australian Journal of Mechanical Engineering, vol. 10, no. 2, pp. 169183, 2012.

[15] A. S. Sait and Y. I. Sharaf-Eldeen, "A review of gearbox condition monitoring based on vibration analysis techniques diagnostics and prognostics," Rotating Machinery, Structural Health Monitoring, Shock and Vibration, Volume 5, vol. 5, pp. 307-324, 2011.

[16] I. Sadeghi, H. Ehya, J. Faiz, and H. Ostovar, “"'Online fault diagnosis of large electrical machines using vibration signal-a review," in," in Proceedings of the 2017 International Conference on Optimization of Electrical and Electronic Equipment (OPTIM) \& 2017 Intl Aegean Conference on Electrical Machines and Power Electronics (ACEMP)., pp. 470-475, Brasov, Romania, May 2017.

[17] B. Kitchenham, S. Charters, D. Budgen et al., Guidelines for Performing Systematic Literature Reviews in Software Engineering, UK, Tech. Rep., Keele University and University of Durham, Keele, England, 2007.

[18] K. Shahzad, P. Cheng, and B. Oelmann, "Architecture exploration for a high-performance and low-power wireless vibration analyzer," IEEE Sensors Journal, vol. 13, no. 2, pp. 670-682, 2012.

[19] C. Scheffer and P. Girdhar, Practical Machinery Vibration Analysis and Predictive Maintenance, Elsevier, Netherlands, Europe, 2004.

[20] M. Nuawi, S. Abdullah, A. Ismail, and N. Kamaruddin, "A novel analysis (i-kaz $3 \mathrm{~d}$ ) for three axial vibration signal in bearing condition monitoring," Statistics, vol. 6, no. 7, pp. 318-322, 2008.

[21] S. Kumar, R. Sehgal, R. Kumar, and S. Bhandari, "Vibrations analysis of 4 jaw flexible coupling considering unbalancing in two planes," International Journal of Science and Technology, vol. 1, no. 11, pp. 602-608, 2012.

[22] Q. He and D. Du, "A new dual-channel analyzer for vibration of rotary machine," in Proceedings oif the ASME Power Conference, pp. 253-256, Orlando, FL, USA, May 2008.

[23] S. A. Ansari and R. Baig, "A pc-based vibration analyzer for condition monitoring of process machinery," IEEE Transactions on Instrumentation and Measurement, vol. 47, no. 2, pp. 378-383, 1998.

[24] A. Gani and M.-J. E. Salami, "A labview based data acquisition system for vibration monitoring and analysis," in Proceedings of the Student Conference on Research and Development, pp. 62-65, Shah Alam, Malaysia, July 2002.

[25] P. Bilski and W. Winiecki, "A low-cost real-time virtual spectrum analyzer," in Proceedings of the IEEE Instrumentation and Measurement Technology Conference, pp. 2216-2221, Ontario, Canada, May 2005.

[26] G. Betta, C. Liguori, A. Paolillo, and A. Pietrosanto, “A dspbased fft-analyzer for the fault diagnosis of rotating machine based on vibration analysis," IEEE Transactions on Instrumentation and Measurement, vol. 51, no. 6, pp. 1316-1322, 2002.

[27] J. D. J. Rangel-Magdaleno, R. D. J. Romero-Troncoso, R. A. Osornio-Rios, E. Cabal-Yepez, and A. DominguezGonzalez, "Fpga-based vibration analyzer for continuous cnc machinery monitoring with fused fft-dwt signal processing," IEEE Transactions on Instrumentation and Measurement, vol. 59, no. 12, pp. 3184-3194, 2010. 
[28] C. Rodriguez-Donate, R. Romero-Troncoso, A. GarciaPerez, and D. A. Razo-Montes, "Fpga based embedded system for induction motor failure monitoring at the start-up transient vibrations with wavelets," in Proceedings of the International Symposium on Industrial Embedded Systems, pp. 208-214, Le Grande Motte, France, June 2008.

[29] G. Betta, C. Liguori, and A. Pietrosanto, "A multi-application $\mathrm{fft}$ analyzer based on a dsp architecture," IEEE Transactions on Instrumentation and Measurement, vol. 50, no. 3, pp. 825-832, 2001.

[30] L. M. Contreras-Medina, R. de Jesus Romero-Troncoso, E. Cabal-Yepez, J. de Jesus Rangel-Magdaleno, and J. R. Millan-Almaraz, "Fpga-based multiple-channel vibration analyzer for industrial applications in induction motor failure detection," IEEE Transactions on Instrumentation and Measurement, vol. 59, no. 1, pp. 63-72, 2009.

[31] M. Kashiwagi, C. d. Costa, and M. H. Mathias, "Digital systems design based on dsp algorithms in fpga for fault identification in rotary machines," Journal of Mechanics \& Industry Research, vol. 2, no. 1, pp. 1-5, 2014.

[32] B. Deb Majumder, J. K. Roy, and S. Padhee, "Recent advances in multifunctional sensing technology on a perspective of multi-sensor system: a review," IEEE Sensors Journal, vol. 19, no. 4, pp. 1204-1214, 2019.

[33] C. Sanders, "A guide to vibration analysis and associated techniques in condition monitoring," 2020, https://www. scribd.com/document/320879762/Vibration-AnalysisGuideaccessed: 20 October 2020.

[34] K. W. Cheung, M. J. Starling, and P. D. McGreevy, "A comparison of uniaxial and triaxial accelerometers for the assessment of physical activity in dogs," Journal of Veterinary Behavior, vol. 9, no. 2, pp. 66-71, 2014.

[35] H. N. Norton, Handbook of Transducers, Prentice-Hall, Hoboken, NJ, USA, 1989.

[36] S. Xianzhong, J. Zhuangde, L. Peng, G. Lin, and J. Xingdong, "A novel pvdf based high-gn shock accelerometer," in Proceedings of the 7th International Symposium on Measurement Technology and Intelligent Instruments, pp. 107110, Huddersfield,England, April 2005.

[37] D. Goyal and B. S. Pabla, "Condition based maintenance of machine tools-A review," CIRP Journal of Manufacturing Science and Technology, vol. 10, pp. 24-35, 2015.

[38] M.-J. E. Salami, A. Gani, and T. Pervez, "Machine condition monitoring and fault diagnosis using spectral analysis techniques," in Proceedings of the 1st International Conference on Mechatronics, pp. 690-700, Kuala Lumpur, Malaysia, June 2001.

[39] J. Igba, K. Alemzadeh, C. Durugbo, and E. T. Eiriksson, "Analysing rms and peak values of vibration signals for condition monitoring of wind turbine gearboxes," Renewable Energy, vol. 91, pp. 90-106, 2016.

[40] A. Khadersab and S. Shivakumar, "Vibration analysis techniques for rotating machinery and its effect on bearing faults," Procedia Manufacturing, vol. 20, pp. 247-252, 2018.

[41] S. B. Chaudhury, M. Sengupta, and K. Mukherjee, "Vibration monitoring of rotating machines using mems accelerometer," International Journal of Scientific Engineering and Research, vol. 2, no. 9, pp. 1-11, 2014.

[42] L. M. Contreras-Medina, R. Romero-Troncoso, J. R. MillanAlmaraz, and C. Rodriguez-Donate, "Fpga based multiplechannel vibration analyzer embedded system for industrial applications in automatic failure detection," in Proceedings of the International Symposium on Industrial Embedded Systems, pp. 229-232, Le Grande Motte, France, June 2008.
[43] J. Doscher, "Adxl105: a lower-noise, wider-bandwidth accelerometer rivals performance of more expensive sensors," Analog Dialogue, vol. 33, no. 6, pp. 27-29, 1999.

[44] S. Thanagasundram and F. S. Schlindwein, "Comparison of integrated micro-electrical-mechanical system and piezoelectric accelerometers for machine condition monitoring," Proceedings of the Institution of Mechanical Engineers - Part C: Journal of Mechanical Engineering Science, vol. 220, no. 8, pp. 1135-1146, 2006.

[45] D. Goyal and B. S. Pabla, "The vibration monitoring methods and signal processing techniques for structural health monitoring: a review," Archives of Computational Methods in Engineering, vol. 23, no. 4, pp. 585-594, 2016.

[46] A. Fernandez, Seismic Velocity Transducers, https://power$\mathrm{mi} . \mathrm{com} /$ content/seismic-velocity-transducers[Online]. Available:, 2020.

[47] M. P. Boyce, Gas Turbine Engineering Handbook, Elsevier, Oxford, England, 2011.

[48] G. Rossi, "Vibration analysis for reciprocating compressors," ORBIT Magazine, vol. 32, no. 2, pp. 10-15, 2012.

[49] A. A. Sarhan, A. Matsubara, S. Ibaraki, and Y. Kakino, "Monitoring of cutting force using spindle displacement sensor," in Proceedings of the Japan - USA Symposium on Flexible Automation, pp. 1-4, Denver, CO, USA, July 2004.

[50] S. M. Saimon, N. H. Ngajikin, M. S. Omar et al., "A low-cost fiber based displacement sensor for industrial applications," TELKOMNIKA (Telecommunication Computing Electronics and Control), vol. 17, no. 2, pp. 555-560, 2019.

[51] S. Binu, V. P. Mahadevan Pillai, and N. Chandrasekaran, "Fibre optic displacement sensor for the measurement of amplitude and frequency of vibration," Optics \& Laser Technology, vol. 39, no. 8, pp. 1537-1543, 2007.

[52] N. Hasheminejad, C. Vuye, W. Van den bergh, J. Dirckx, and S. Vanlanduit, "A comparative study of laser Doppler vibrometers for vibration measurements on pavement materials," Infrastructure, vol. 3, no. 4, p. 47, 2018.

[53] X. Ma, M. Li, L. Ye et al., "Research on self calibration technology for precision workpiece measurement based on laser Doppler vibrometer," Integrated Ferroelectrics, vol. 199, no. 1, pp. 160-171, 2019.

[54] S. J. Rothberg, M. S. Allen, P. Castellini et al., "An international review of laser Doppler vibrometry: making light work of vibration measurement," Optics and Lasers in Engineering, vol. 99, pp. 11-22, 2017.

[55] I. Howard, "A review of rolling element bearing vibration'detection, diagnosis and prognosis," Report for the Defence Science and Technology Organization Canberra (Australia). Report no. DSTO-RR-0013, October. Victoria," DSTO Aeronautical and Maritime Research Laboratory., Tech. Rep., Melbourne, Victoria, Australia, 1994.

[56] P. Gangsar and R. Tiwari, "Multiclass fault taxonomy in rolling bearings at interpolated and extrapolated speeds based on time domain vibration data by svm algorithms," Journal of Failure Analysis and Prevention, vol. 14, no. 6, pp. 826-837, 2014.

[57] S. Lahdelma and E. Juuso, "Signal processing in vibration analysis," in Proceedings of the 5th International Conference on Condition Monitoring and Machinery Failure Prevention Technologies, pp. 867-878, Edinburgh, Scotland, July 2008.

[58] A. Shrivastava and S. Wadhwani, "An approach for fault detection and diagnosis of rotating electrical machine using vibration signal analysis," in Proceedings of the International Conference on Recent Advances and Innovations in Engineering, pp. 1-6, Jaipur, India, May 2014. 
[59] M. Vishwakarma, R. Purohit, V. Harshlata, and P. Rajput, "Vibration analysis \& condition monitoring for rotating machines: a review," Materials Today: Proceedings, vol. 4, no. 2, pp. 2659-2664, 2017.

[60] W. Bartelmus, F. Chaari, R. Zimroz, and M. Haddar, "Modelling of gearbox dynamics under time-varying nonstationary load for distributed fault detection and diagnosis," European Journal of Mechanics - A: Solids, vol. 29, no. 4, pp. 637-646, 2010.

[61] J. Sheldon, G. Mott, H. Lee, and M. Watson, "Robust wind turbine gearbox fault detection," Wind Energy, vol. 17, no. 5, pp. 745-755, 2014.

[62] A. Krishnakumari, A. Elayaperumal, M. Saravanan, and C. Arvindan, "Fault diagnostics of spur gear using decision tree and fuzzy classifier," International Journal of Advanced Manufacturing Technology, vol. 89, no. 9-12, pp. 3487-3494, 2017.

[63] B. Samanta and K. R. Al-Balushi, "Artificial neural network based fault diagnostics of rolling element bearings using time-domain features," Mechanical Systems and Signal Processing, vol. 17, no. 2, pp. 317-328, 2003.

[64] Z. Chen, X. Chen, C. Li, R.-V. Sanchez, and H. Qin, "Vibration-based gearbox fault diagnosis using deep neural networks," Journal of Vibroengineering, vol. 19, no. 4, pp. 2475-2496, 2017.

[65] L. Jiang, Y. Liu, X. Li, and A. Chen, "Gear fault diagnosis based on svm and multi-sensor information fusion," Journal of Central South University, vol. 41, no. 6, pp. 2184-2188, 2010.

[66] N. Aiswarya, S. Suja Priyadharsini, and K. Moni, "An efficient approach for the diagnosis of faults in turbo pump of liquid rocket engine by employing $\mathrm{ftt}$ and time-domain features," Australian Journal of Mechanical Engineering, vol. 16, no. 3, pp. 163-172, 2018.

[67] J. Runesson, "Vibration analysis for condition monitoring of mechanical presses," Master's Thesis, Lund University, Lund, Sweden, 2019.

[68] P. H. Westfall, "Kurtosis as p," The American Statistician, vol. 68, no. 3, pp. 191-195, 2014.

[69] J. Hebda-Sobkowicz, R. Zimroz, and A. Wyłomańska, "Selection of the informative frequency band in a bearing fault diagnosis in the presence of non-Gaussian noise-comparison of recently developed methods," Applied Sciences, vol. 10, no. 8, p. 2657, 2020.

[70] S. Fu, K. Liu, Y. Xu, and Y. Liu, "Rolling bearing diagnosing method based on time domain analysis and adaptive fuzzymeans clustering," Shock and Vibration, vol. 2016, 2016.

[71] K. H. Zhu, X. G. Song, and D. X. Xue, "Roller bearing fault diagnosis based on imf kurtosis and svm," Advanced Materials Research, vol. 694-697, pp. 1160-1166, 2013.

[72] H. K. Patel, D. Shah, and A. Raghuwanshi, "Real time machine health monitoring and vibrational analysis using $\mathrm{fft}$ approach," International Journal of Engineering and Advanced Technology, vol. 8, no. 5, pp. 1833-1836, 2019.

[73] T. Ameid, A. Menacer, H. Talhaoui, and I. Harzelli, "Broken rotor bar fault diagnosis using fast fourier transform applied to field-oriented control induction machine: simulation and experimental study," International Journal of Advanced Manufacturing Technology, vol. 92, no. 1-4, pp. 917-928, 2017.

[74] Y. Liu, Z. Jiang, H. Haizhou, and J. Xiang, “Asymmetric penalty sparse model based cepstrum analysis for bearing fault detections," Applied Acoustics, vol. 165, p. 107288, 2020.
[75] G. Dalpiaz, A. Rivola, and R. Rubini, "Gear fault monitoring: comparison of vibration analysis techniques," in Proceedings of the 3rd International Conference Acoustical and Vibratory Surveillance Methods and Diagnostics Techniques, pp. 623632, Las Vegas, NV, USA, January 1998.

[76] T. Sako, K. Tokumo, and O. Yoshie, "Rubbing detection of sliding bearings in early stage by frequency modulation analysis," Electronics and Communications in Japan, vol. 97, no. 12, pp. 11-23, 2014.

[77] S. S. Aralikatti, K. Ravikumar, and H. Kumar, "Fault diagnosis of single point cutting tool using spectrum, cepstrum and wavelet analysis," in Proceedings of the 1st International Conference on Manufacturing, Material Science and Engineering, pp. 1-9, Telangana, India, August 2019.

[78] H. Li, Y. Zhang, and H. Zheng, "Gear fault detection and diagnosis under speed-up condition based on order cepstrum and radial basis function neural network," Journal of Mechanical Science and Technology, vol. 23, no. 10, pp. 2780-2789, 2009.

[79] C. Peeters, P. Guillaume, and J. Helsen, “A comparison of cepstral editing methods as signal pre-processing techniques for vibration-based bearing fault detection," Mechanical Systems and Signal Processing, vol. 91, pp. 354-381, 2017.

[80] R. B. Randall, Frequency Analysis, Bruel and Kjaer, Copenhagen, Denmark, 1987.

[81] D. Abboud, J. Antoni, S. Sieg-Zieba, and M. Eltabach, "Envelope analysis of rotating machine vibrations in variable speed conditions: a comprehensive treatment," Mechanical Systems and Signal Processing, vol. 84, pp. 200-226, 2017.

[82] D. Ho and R. B. Randall, "Optimisation of bearing diagnostic techniques using simulated and actual bearing fault signals," Mechanical Systems and Signal Processing, vol. 14, no. 5, pp. 763-788, 2000.

[83] R. Rubini and U. Meneghetti, "Application of the envelope and wavelet transform analyses for the diagnosis of incipient faults in ball bearings," Mechanical Systems and Signal Processing, vol. 15, no. 2, pp. 287-302, 2001.

[84] A. Widodo, E. Y. Kim, J.-D. Son et al., "Fault diagnosis of low speed bearing based on relevance vector machine and support vector machine," Expert Systems with Applications, vol. 36, no. 3, pp. 7252-7261, 2009.

[85] V. C. M. N. Leite, J. G. B. Da Silva, G. F. C. Veloso et al., "Detection of localized bearing faults in induction machines by spectral kurtosis and envelope analysis of stator current," IEEE Transactions on Industrial Electronics, vol. 62, no. 3, pp. 1855-1865, 2014.

[86] R. B. Randall, J. Antoni, and S. Chobsaard, "The relationship between spectral correlation and envelope analysis in the diagnostics of bearing faults and other cyclostationary machine signals," Mechanical Systems and Signal Processing, vol. 15, no. 5, pp. 945-962, 2001.

[87] J. Trout, "Vibration analysis explained," 2020, https://www. reliableplant.com/vibration-analysis-31569[Online]. Available:.

[88] P. J. Loughlin and G. D. Bernard, "Cohen-posch (positive) time-frequency distributions and their application to machine vibration analysis," Mechanical Systems and Signal Processing, vol. 11, no. 4, pp. 561-576, 1997.

[89] L. Ciabattoni, F. Ferracuti, A. Freddi, and A. Monteriu, "Statistical spectral analysis for fault diagnosis of rotating machines," IEEE Transactions on Industrial Electronics, vol. 65, no. 5, pp. 4301-4310, 2017.

[90] J. Cui, Y.-R. Wang, and Q. Liu, “The technique of power electronic circuit fault diagnosis based on higher-order 
spectrum analysis and support vector machines," In Proceedings of the Chinese Society of Electrical Engineering, vol. 27, no. 10, pp. 62-66, 2007.

[91] T. Guishuang, S. Wang, and C. Zhang, "A method for rolling bearing fault diagnosis based on the power spectrum analysis and support vector machine," in Proceedings of the IEEE 10th International Conference on Industrial Informatics, pp. 546-549, Beijing, China, July 2012.

[92] Z. Feng, M. Liang, and F. Chu, "Recent advances in timefrequency analysis methods for machinery fault diagnosis: a review with application examples," Mechanical Systems and Signal Processing, vol. 38, no. 1, pp. 165-205, 2013.

[93] Y. Wei, Y. Li, M. Xu, and W. Huang, "A review of early fault diagnosis approaches and their applications in rotating machinery," Entropy, vol. 21, no. 4, p. 409, 2019.

[94] G. Dalpiaz and A. Rivola, "Condition monitoring and diagnostics in automatic machines: comparison of vibration analysis techniques," Mechanical Systems and Signal Processing, vol. 11, no. 1, pp. 53-73, 1997.

[95] B. Bao Liu, S.-F. Ling, and Q. Qingfeng Meng, "Machinery diagnosis based on wavelet packets," Journal of Vibration and Control, vol. 3, no. 1, pp. 5-17, 1997.

[96] J. Zou and J. Chen, "“A comparative study on time-frequency feature of cracked rotor by wigner-ville distribution and wavelet transform," Journal of Sound and Vibration, vol. 276, no. 1-2, pp. 1-11, 2004.

[97] A. Giantomassi, F. Ferracuti, S. Iarlori, G. Ippoliti, and S. Longhi, "Electric motor fault detection and diagnosis by kernel density estimation and kullback-leibler divergence based on stator current measurements," IEEE Transactions on Industrial Electronics, vol. 62, no. 3, pp. 1770-1780, 2015.

[98] F. Al-Badour, M. Sunar, and L. Cheded, "Vibration analysis of rotating machinery using time-frequency analysis and wavelet techniques," Mechanical Systems and Signal Processing, vol. 25, no. 6, pp. 2083-2101, 2011.

[99] J. Rangel-Magdaleno, H. Peregrina-Barreto, J. RamirezCortes, R. Morales-Caporal, and I. Cruz-Vega, "Vibration analysis of partially damaged rotor bar in induction motor under different load condition using dwt," Shock and Vibration, vol. 2016, Article ID 3530464, 11 pages, 2016.

[100] G. G. Yen and K.-C. Lin, "Wavelet packet feature extraction for vibration monitoring," IEEE Transactions on Industrial Electronics, vol. 47, no. 3, pp. 650-667, 2000.

[101] J. Lin and L. Qu, "Feature extraction based on morlet wavelet and its application for mechanical fault diagnosis," Journal of Sound and Vibration, vol. 234, no. 1, pp. 135-148, 2000.

[102] X. Fan and M. J. Zuo, "Gearbox fault detection using hilbert and wavelet packet transform," Mechanical Systems and Signal Processing, vol. 20, no. 4, pp. 966-982, 2006.

[103] W. Fan, Q. Zhou, J. Li, and Z. Zhu, "A wavelet-based statistical approach for monitoring and diagnosis of compound faults with application to rolling bearings," IEEE Transactions on Automation Science and Engineering, vol. 15, no. 4, pp. 1563-1572, 2017.

[104] V. Climente-Alarcon, J. A. Antonino-Daviu, M. RieraGuasp, R. Puche-Panadero, and L. Escobar, "Application of the Wigner-Ville distribution for the detection of rotor asymmetries and eccentricity through high-order harmonics," Electric Power Systems Research, vol. 91, pp. 28-36, 2012.

[105] W. J. Staszewski, K. Worden, and G. R. Tomlinson, “Timefrequency analysis in gearbox fault detection using the wigner-ville distribution and pattern recognition,"
Mechanical Systems and Signal Processing, vol. 11, no. 5, pp. 673-692, 1997.

[106] Y.-S. Han and C.-W. Lee, "Directional Wigner distribution for order analysis in rotating/reciprocating machines," Mechanical Systems and Signal Processing, vol. 13, no. 5, pp. 723-737, 1999.

[107] N. Baydar and A. Ball, "A comparative study of acoustic and vibration signals in detection of gear failures using wignerville distribution," Mechanical Systems and Signal Processing, vol. 15, no. 6, pp. 1091-1107, 2001.

[108] N. E. Huang, Z. Shen, S. R. Long et al., "The empirical mode decomposition and the hilbert spectrum for nonlinear and non-stationary time series analysis," Proceedings of the Royal Society of London. Series A: Mathematical, Physical and Engineering Sciences, vol. 454, no. 1971, pp. 903-995, 1998.

[109] S. Huang, X. Wang, C. Li, and C. Kang, "Data decomposition method combining permutation entropy and spectral substitution with ensemble empirical mode decomposition," Measurement, vol. 139, pp. 438-453, 2019.

[110] M. E. Torres, M. A. Colominas, G. Schlotthauer, and P. Flandrin, "A complete ensemble empirical mode decomposition with adaptive noise," in Proceedings of the IEEE International Conference on Acoustics, Speech and Signal Processing (ICASSP), pp. 4144-4147, Prague, Czech Republic, May 2011.

[111] Z. K. Peng, P. W. Tse, and F. L. Chu, "A comparison study of improved Hilbert-Huang transform and wavelet transform: application to fault diagnosis for rolling bearing," $\mathrm{Me}$ chanical Systems and Signal Processing, vol. 19, no. 5, pp. 974-988, 2005.

[112] T. Wu, Y. Chung, and C. Liu, "“'Looseness diagnosis of rotating machinery via vibration analysis through hilbert-huang transform approach," Journal of Vibration and Acoustics, vol. 132, no. 3, pp. 1-9, 2010.

[113] S. Osman and W. Wang, "A normalized hilbert-huang transform technique for bearing fault detection," Journal of Vibration and Control, vol. 22, no. 11, pp. 2771-2787, 2016.

[114] W. Chen, J. Li, Q. Wang, and K. Han, "Fault feature extraction and diagnosis of rolling bearings based on wavelet thresholding denoising with ceemdan energy entropy and pso-lssvm," Measurement, vol. 172, Article ID 108901, 2020.

[115] Z. Y. Xuan and M. Ge, "Application of the hilbert - huang transform for machine fault diagnostics," Applied Mechanics and Materials, vol. 182-183, pp. 1484-1488, 2012.

[116] M. Rezaee and A. Taraghi Osguei, "Improving empirical mode decomposition for vibration signal analysis," Proceedings of the Institution of Mechanical Engineers - Part C: Journal of Mechanical Engineering Science, vol. 231, no. 12, pp. 2223-2234, 2017.

[117] D. Gabor, "Theory of communication. part 1: the analysis of information," Journal of the Institution of Engineers: Electronics, vol. 93, no. 26, pp. 429-441, 1946.

[118] M. Safizadeh, A. Lakis, and M. Thomas, "Using short-time fourier transform in machinery diagnosis," in Proceedings of the 4th WSEAS International Conference on Electronic, Signal Processing and Control, pp. 1-7, Rio de Janeiro, Brazil, April 2005.

[119] J. Burriel-Valencia, R. Puche-Panadero, J. Martinez-Roman, A. Sapena-Bano, and M. Pineda-Sanchez, "Short-frequency fourier transform for fault diagnosis of induction machines working in transient regime," IEEE Transactions on Instrumentation and Measurement, vol. 66, no. 3, pp. 432-440, 2017. 
[120] Z. Wu, Y. Li, H. Liu, and L. Liu, "Application of short-time fourier transform in the vibration analysis of the large hydroelectric machine," Journal of Hydroelectric Engineering, vol. 24, no. 6, pp. 115-120, 2005.

[121] T. P. Banerjee, S. Das, J. Roychoudhury, and A. Abraham, "Implementation of a new hybrid methodology for fault signal classification using short -time fourier transform and support vector machines," in Soft Computing Models in Industrial and Environmental, E. Corchado, P. Novais, C. Analide, and J. Sedano, Eds., Springer, Berlin, Germany, pp. 219-225, 2010.

[122] H. Gao, L. Liang, X. Chen, and G. Xu, "Feature extraction and recognition for rolling element bearing fault utilizing short-time fourier transform and non-negative matrix factorization," Chinese Journal of Mechanical Engineering, vol. 28, no. 1, pp. 96-105, 2015.

[123] K. Mollazade, H. Ahmadi, M. Omid, and R. Alimardani, "An intelligent combined method based on power spectral density, decision trees and fuzzy logic for hydraulic pumps fault diagnosis," International Journal of Intelligent Systems and Technologies, vol. 3, no. 4, pp. 251-263, 2008.

[124] J. Cusid, L. Romeral, J. A. Ortega, J. A. Rosero, and A. Garcia Espinosa, "Fault detection in induction machines using power spectral density in wavelet decomposition," IEEE Transactions on Industrial Electronics, vol. 55, no. 2, pp. 633-643, 2008.

[125] K. Heidarbeigi, H. Ahmadi, and M. Omid, "Fault diagnosis of massey ferguson gearbox using power spectral density," in Proceedings of the 18th International Conference on Electrical Machines, pp. 1-4, Vilamoura, Portugal, September 2008.

[126] M. Heydarzadeh, N. Madani, and M. Nourani, "Gearbox fault diagnosis using power spectral analysis," in Proceedings of the IEEE International Workshop on Signal Processing Systems, pp. 242-247, Dallas, TX, USA, October 2016.

[127] D. Dou and S. Zhou, "Comparison of four direct classification methods for intelligent fault diagnosis of rotating machinery," Applied Soft Computing, vol. 46, pp. 459-468, 2016.

[128] A. A. Pinheiro, I. M. Brandao, and C. Da Costa, "Vibration analysis in turbomachines using machine learning techniques," European Journal of Engineering Research and Science, vol. 4, no. 2, pp. 12-16, 2019.

[129] O. AlShorman, M. Irfan, N. Saad et al., "A review of artificial intelligence methods for condition monitoring and fault diagnosis of rolling element bearings for induction motor," Shock and Vibration, vol. 2020, Article ID 8843759, 20 pages, 2020.

[130] S. Poyhonen, M. Negrea, A. Arkkio, H. Hyotyniemi, and H. Koivo, "Support vector classification for fault diagnostics of an electrical machine," in Proceedings of the 6th International Conference on Signal Processing, pp. 1719-1722, Beijing, China, October 2002.

[131] A. Tabrizi, L. Garibaldi, A. Fasana, and S. Marchesiello, "Early damage detection of roller bearings using wavelet packet decomposition, ensemble empirical mode decomposition and support vector machine," Meccanica, vol. 50, no. 3, pp. 865-874, 2015.

[132] C. Wu, T. Chen, R. Jiang, L. Ning, and Z. Jiang, “A novel approach to wavelet selection and tree kernel construction for diagnosis of rolling element bearing fault," Journal of Intelligent Manufacturing, vol. 28, no. 8, pp. 1847-1858, 2017.

[133] J. Yang, Y. Zhang, and Y. Zhu, "Intelligent fault diagnosis of rolling element bearing based on svms and fractal dimension," Mechanical Systems and Signal Processing, vol. 21, no. 5, pp. 2012-2024, 2007.

[134] A. Moosavian, H. Ahmadi, and A. Tabatabaeefar, "Fault diagnosis of main engine journal bearing based on vibration analysis using Fisher linear discriminant, k-nearest neighbor and support vector machine," Journal of Vibroengineering, vol. 14, no. 2, pp. 894-906, 2012.

[135] Y. Zhu, Q. Yan, and J. Lu, "Fault diagnosis method for disc slitting machine based on wavelet packet transform and support vector machine," International Journal of Computer Integrated Manufacturing, vol. 33, no. 10-11, pp. 1118-1128, 2020.

[136] J. Runge and R. Zmeureanu, "Forecasting energy use in buildings using artificial neural networks: a review," Energies, vol. 12, no. 17, p. 3254, 2019.

[137] M. R. Castelino, H. S. Kumar, P. P. Srinivasa, and G. S. Vijay, "Artificial neural network-based vibration signal analysis of rotary machines-case studies," in Proceedings of the International Conference on Emerging Trends in Engineering, pp. 211-218, Karnataka, India, July 2014.

[138] G. Zurita, V. Sanchez, and D. Cabrera, "A review of vibration machine diagnostics by using artificial intelligence methods," Revista Investigacion and Desarrollo, vol. 1, no. 16, pp. 102-114, 2016.

[139] M. A. Korany, H. Mahgoub, O. T. Fahmy, and H. M. Maher, "Application of artificial neural networks for response surface modelling in hplc method development," Journal of Advanced Research, vol. 3, no. 1, pp. 53-63, 2012.

[140] H. M. Ertunc, H. Ocak, and C. Aliustaoglu, "Ann-and anfisbased multi-staged decision algorithm for the detection and diagnosis of bearing faults," Neural Computing \& Applications, vol. 22, no. 1, pp. 435-446, 2013.

[141] Y. Chen, X. Qin, J. Wang, C. Yu, and W. Gao, "FedHealth: a federated transfer learning framework for wearable healthcare," IEEE Intelligent Systems, vol. 35, no. 4, pp. 83-93, 2020.

[142] D.-T. Hoang and H.-J. Kang, "Rolling element bearing fault diagnosis using convolutional neural network and vibration image," Cognitive Systems Research, vol. 53, pp. 42-50, 2019.

[143] W. Qian, S. Li, J. Wang, Y. Xin, and H. Ma, "A new deep transfer learning network for fault diagnosis of rotating machine under variable working conditions," in Proceedings of the 2018 Prognostics and System Health Management Conference, pp. 1010-1016, Chongqing, China, October 2018.

[144] F. Yang, W. Zhang, L. Tao, and J. Ma, "Transfer learning strategies for deep learning-based phm algorithms," Applied Sciences, vol. 10, no. 7, p. 2361, 2020.

[145] B. Samanta, K. R. Al-Balushi, and S. A. Al-Araimi, "Artificial neural networks and genetic algorithm for bearing fault detection," Soft Computing, vol. 10, no. 3, pp. 264-271, 2006.

[146] Y. Yu and C. Junsheng, "A roller bearing fault diagnosis method based on emd energy entropy and ann," Journal of Sound and Vibration, vol. 294, no. 1-2, pp. 269-277, 2006.

[147] F. Bi and Y. Liu, "Fault diagnosis of valve clearance in diesel engine based on bp neural network and support vector machine," Transactions of Tianjin University, vol. 22, no. 6, pp. 536-543, 2016.

[148] M. M. M. Islam and J.-M. Kim, "Motor bearing fault diagnosis using deep convolutional neural networks with $2 \mathrm{~d}$ analysis of vibration signal," Advances in Artificial Intelligence, Springer, in Proceedings of the Canadian Conference on Artificial Intelligence, pp. 144-155, May 2018.

[149] S. Xing, Y. Lei, S. Wang, and F. Jia, "Distribution-invariant deep belief network for intelligent fault diagnosis of 
machines under new working conditions," IEEE Transactions on Industrial Electronics, vol. 68, no. 3, pp. 2617-2625, 2020.

[150] D. Kolar, D. Lisjak, M. Pająk, and D. Pavković, "Fault diagnosis of rotary machines using deep convolutional neural network with wide three axis vibration signal input," Sensors, vol. 20, no. 14, p. 4017, 2020.

[151] M. He and D. He, "A new hybrid deep signal processing approach for bearing fault diagnosis using vibration signals," Neurocomputing, vol. 396, pp. 542-555, 2020.

[152] L. Xueyi, L. Jialin, Q. Yongzhi, and H. David, "Semi-supervised gear fault diagnosis using raw vibration signal based on deep learning," Chinese Journal of Aeronautics, vol. 33, no. 2, pp. 418-426, 2020.

[153] L. A. Zadeh, "Fuzzy logic," Computer, vol. 21, no. 4, pp. 83-93, 1988.

[154] J. Serrano-Guerrero, F. P. Romero, and J. A. Olivas, "Fuzzy logic applied to opinion mining: a review," knowledge-based systems," Knowledge-Based Systems, vol. 222, Article ID 107018, 2021.

[155] P. Jayaswal, A. K. Wadhwani, and K. B. Mulchandani, "Machine fault signature analysis," International Journal of Rotating Machinery, vol. 2008, pp. 1-10, 2008.

[156] J. M. F. Salido and S. Murakami, "A comparison of two learning mechanisms for the automatic design of fuzzy diagnosis systems for rotating machinery," Applied Soft Computing, vol. 4, no. 4, pp. 413-422, 2004.

[157] I. Lasurt, A. F. Stronach, and J. Penman, "A fuzzy logic approach to the interpretation of higher order spectra applied to fault diagnosis in electrical machines," in Proceedings of the 19th International Conference of the North American Fuzzy Information Processing Society, pp. 158-162, Atlanta, GA, , USA, July 2000.

[158] J.-D. Wu and C.-C. Hsu, "Fault gear identification using vibration signal with discrete wavelet transform technique and fuzzy-logic inference," Expert Systems with Applications, vol. 36, no. 2, pp. 3785-3794, 2009.

[159] R. V. Mukane, N. M. Gurav, S. Y. Sondkar, and N. C. Fernandes, "Labview based implementation of fuzzy logic for vibration analysis to identify machinery faults," in Proceedings of the International Conference on Computing, Communication, Control and Automation, pp. 1-5, Pune, India, August 2017.

[160] R. F. M. Marcal, M. Negreiros, A. A. Susin, and J. L. Kovaleski, "Detecting faults in rotating machines," IEEE Instrumentation and Measurement Magazine, vol. 3, no. 4, pp. 24-26, 2000.

[161] J. Wang and $\mathrm{H}$. Hu, "Vibration-based fault diagnosis of pump using fuzzy technique," Measurement, vol. 39, no. 2, pp. 176-185, 2006.

[162] A. Umbrajkaar and A. Krishnamoorthy, "Vibration analysis using wavelet transform and fuzzy logic for shaft misalignment," Journal of Vibroengineering, vol. 20, no. 8, pp. 2855-2865, 2018.

[163] B. Alili, A. Hafaifa, and A. Iratni, "Faults detection based on fuzzy concepts for vibrations monitoring in gas turbine," Diagnostyka, vol. 21, no. 4, pp. 67-77, 2020.

[164] J. Kusyk, C. S. Sahin, M. Umit Uyar, E. Urrea, and S. Gundry, "Self-organization of nodes in mobile ad hoc networks using evolutionary games and genetic algorithms," Journal of Advanced Research, vol. 2, no. 3, pp. 253-264, 2011.

[165] S. Katoch, S. S. Chauhan, and V. Kumar, "A review on genetic algorithm: past, present, and future," Multimedia Tools and Applications, vol. 80, no. 5, pp. 8091-8126, 2021.
[166] T. Han, B. S. Yang, and Z. J. Yin, "Feature-based fault diagnosis system of induction motors using vibration signal," Journal of Quality in Maintenance Engineering, vol. 13, no. 2, pp. 163-175, 2007.

[167] A. Hajnayeb, A. Ghasemloonia, S. E. Khadem, and M. H. Moradi, "Application and comparison of an ann-based feature selection method and the genetic algorithm in gearbox fault diagnosis," Expert Systems with Applications, vol. 38, no. 8, pp. $10205-10209,2011$.

[168] F. Chen, B. Tang, and R. Chen, "A novel fault diagnosis model for gearbox based on wavelet support vector machine with immune genetic algorithm," Measurement, vol. 46, no. 1, pp. 220-232, 2013.

[169] C. Y. Xiao, B. Q. Shi, Z. J. Hao, and S. M. Zhu, "Gear incipient diagnosing based on eemd and genetic-support vector machine," Applied Mechanics and Materials, vol. 397-400, pp. 2104-2110, 2013.

[170] R. Semil and P. Jaiswal, "Bearing fault diagnosis using support vector machine with genetic algorithms based optimization and $\mathrm{k}$ fold cross-validation method," International Journal of Recent Technology and Engineering, vol. 8, no. 2, pp. 3242-3250, 2019.

[171] A. Afia, C. Rahmoune, and D. Benazzouz, "Gear fault diagnosis using autogram analysis," Advances in Mechanical Engineering, vol. 10, no. 12, Article ID 1687814018812534, 2018.

[172] J. Nowicki, J. Hebda-Sobkowicz, R. Zimroz, and A. Wyłomańska, "Dependency measures for the diagnosis of local faults in application to the heavy-tailed vibration signal," Applied Acoustics, vol. 178, Article ID 107974, 2021.

[173] T. Fei, C. Jiangfeng, Q. Qinglin, M. Zhang, H. Zhang, and S. Fangyuan, "Digital twin-driven product design, manufacturing and service with big data," International Journal of Advanced Manufacturing Technology, vol. 94, no. 9-12, pp. 3563-3576, 2018.

[174] D. Shangguan, L. Chen, and J. Ding, “A digital twin-based approach for the fault diagnosis and health monitoring of a complex satellite system," Symmetry, vol. 12, no. 8, p. 1307, 2020.

[175] J. Wang, L. Ye, R. X. Gao, C. Li, and L. Zhang, "Digital twin for rotating machinery fault diagnosis in smart manufacturing," International Journal of Production Research, vol. 57, no. 12, pp. 3920-3934, 2019. 